\title{
miRNA-21 ablation protects against liver injury and necroptosis in cholestasis
}

\author{
Marta B. Afonso ${ }^{1}$ Pedro M. Rodrigues $\mathbb{1}^{1} \cdot$ André L. Simão $^{1}$ Maria M. Gasparr ${ }^{1}$ Tânia Carvalho ${ }^{2}$. \\ Paula Borralho ${ }^{3,4,5} \cdot$ Jesús M. Bañales ${ }^{6} \cdot$ Rui E. Castro ${ }^{1} \cdot$ Cecília M.P. Rodrigues $^{1}$
}

Received: 7 August 2017 / Revised: 10 October 2017 / Accepted: 20 October 2017 / Published online: 11 December 2017

๑) ADMC Associazione Differenziamento e Morte Cellulare 2018

\begin{abstract}
Inhibition of microRNA-21 (miR-21) prevents necroptosis in the mouse pancreas. Necroptosis contributes to hepatic necroinflammation in the common bile duct ligation (BDL) murine model. We aimed to evaluate the role of miR-21 in mediating deleterious processes associated with cholestasis. Mechanistic studies established a functional link between miR-21 and necroptosis through cyclin-dependent kinase 2-associated protein 1 (CDK2AP1). miR-21 expression increased in the liver of primary biliary cholangitis (PBC) patients and BDL wild-type (WT) mice at both 3 and 14 days. Notably, under BDL, miR$21^{-/}$mice displayed decreased liver injury markers in serum compared with WT mice, accompanied by reduced hepatocellular degeneration, oxidative stress and fibrosis. Hallmarks of necroptosis were decreased in the liver of BDL $m i R$ $21^{-/-}$mice, via relieved repression of CDK2AP1. Further, $m i R-21^{-/}$mice displayed improved adaptive response of bile acid homeostasis. In conclusion, miR-21 ablation ameliorates liver damage and necroptosis in BDL mice. Inhibition of miR21 should arise as a promising approach to treat cholestasis.
\end{abstract}

\section{Introduction}

Necrosis can occur as a genetically controlled process, amenable to therapeutic targeting [1]. Necroptosis is the most understood regulated necrosis pathway that critically depends on receptor-interacting protein 3 (RIP3) kinase and

Edited by S. Kaufmann

CecíliaM.P. Rodrigues

cmprodrigues@ff.ul.pt

1 Research Institute for Medicines (iMed.ULisboa), Faculty of Pharmacy, Universidade de Lisboa, Lisbon, Portugal

2 Histology and Comparative Pathology Laboratory, Instituto de Medicina Molecular, Lisbon, Portugal

3 Escola Superior de Tecnologia da Saúde de Lisboa (ESTEsL), Lisbon, Portugal

4 Instituto de Anatomia Patológica, Universidade de Lisboa, Lisbon, Portugal

5 Hospital Cuf Descobertas, Lisbon, Portugal

6 Department of Liver and Gastrointestinal Diseases, Biodonostia Research Institute - Donostia University Hospital - University of the Basque Country (UPV/EHU), CIBERehd, Ikerbasque, San Sebastian, Spain mixed lineage kinase domain-like (MLKL) activation [2]. Necroptosis and apoptosis have overlapped molecular machineries, including death receptor activation. Nevertheless, execution of necroptosis encompasses a unique active disintegration of plasma membranes by MLKL upon phosphorylation by RIP3 [3,4].

Unwarranted activation of necroptosis contributes to the pathogenesis of several conditions, including liver diseases [3,5-7]. We recently showed that necroptosis is activated in the liver of patients with primary biliary cholangitis (PBC) [8], associated with cholestasis and often end-stage liver disease [9]. However, using the common bile duct ligation (BDL) murine model, a classic experimental model of acute cholestasis and secondary biliary fibrosis [10], we found that deletion of RIP3 prevents hepatic necro-inflammation, but it is insufficient to halt fibrosis [8].

Given the relatively new concept of programmed necrosis, the knowledge on regulation of necroptosis by microRNAs (miRNAs/miRs) $[11,12]$ is still scarce. Ablation of miR-21 protects mice from necroptosis in murine models of acute pancreatitis and tumor necrosis factor (TNF)- $\alpha$-induced shock [13]. Of note, miR21 is upregulated in the liver of patients with cholangiocarcinoma [14], hepatocellular carcinoma [15], non-alcoholic steatohepatitis [16-18], and cholestatic liver injury $[19,20]$. Since miR-21 regulates hepatic 
stellate activation and liver fibrosis in BDL mice [19], targeting miR-21 might constitute a novel approach to prevent both necroptosis-associated liver injury and fibrosis.

In the present study, we show that miR-21 modulates necroptosis in L929 cells and primary mouse hepatocytes via targeting of cell cycle regulator cyclin-dependent kinase 2-associated protein 1 (CDK2AP1). miR-21 expression increased in the liver of PBC patients and BDL mice. Further, miR-21 ablation ameliorates necroptosis and liver damage in BDL mice, via CDK2AP1, concomitantly with improved adaptive responses of bile acid homeostasis gene expression.

\section{Results}

\section{miR-21 modulates necroptosis in primary mouse hepatocytes}

Primary mouse hepatocytes isolated from wild-type (WT), Rip $^{-l-}$ and $m i R-21^{-l-}$ mice were pre-treated with $\mathrm{ZVAD}$ fmk, a pan-caspase inhibitor, and then loaded with a combination of TNF- $\alpha$ and cycloheximide (CHX) to promote necroptosis [5]. Remarkably, cell death was completely abrogated in both Rip $3^{-/-}$and $m i R-21^{-1-}$ mouse hepatocytes compared with WT $(p<0.05)$, as assessed by loss of plasma membrane integrity (Fig. 1a). Accordingly, TNF- $\alpha /$ CHX/zVAD-fmk-induced MLKL phosphorylation, a biological marker of necroptosis, was diminished in primary mouse hepatocytes isolated from $R i p 3^{-/-}$and $m i R-21^{-1-}$ mice $(p<0.05$; Fig. 1b). After TNF- $\alpha / C H X / z V A D-f m k$ stimulation, miR-21-deficiency shifted the pattern of phosphorylated MLKL (p-MLKL) distribution from insoluble to soluble fractions, which precludes necroptosis execution (Fig. 1c).

In gain-of-function experiments, WT primary mouse hepatocytes were transfected with a miR-21 precursor, both in the presence and absence of TNF- $\alpha / \mathrm{CHX} / \mathrm{zVAD}$-fmk (Fig. 1d). TNF- $\alpha / \mathrm{CHX} / \mathrm{zVAD}$-fmk-induced necroptosis was strongly exacerbated $(p<0.01$ vs. pre-miR Control; Fig. 1e). Further, p-MLKL accumulated in the insoluble protein fraction in hepatocytes overexpressing miR-21 $(p<$ 0.01 ; Fig. 1f).

L929 fibrosarcoma cells have been reported to rapidly undergo necroptosis in vitro in response to TNF- $\alpha$, providing a well-established cell system to analyze general aspects of necroptosis. In agreement, silencing of miR-21 through transfection with anti-miR-21 decreased necroptotic cell death induced by TNF- $\alpha(p<0.05$; Fig. 2a), while overexpression of miR-21 aggravated necroptosis $(p<0.05$; Fig. 2b). This constitutes proof-of-concept that miR-21 modulates necroptosis.

\section{Deletion of miR-21 protects primary mouse hepatocytes from necroptosis via CDK2AP1}

Primary mouse hepatocytes isolated from WT or $m i R-21^{-I-}$ mice were transfected with a specific siRNA against either phosphatase and tensin homolog (PTEN), programmed cell death protein 4 (PDCD4), and CDK2AP1, well-established targets of miR-21 associated with cell death and proliferation. Upon silencing, total protein levels of PTEN and PDCD4 were reduced by $50-60 \%$ in both WT and $m i R$ $21^{-l-}$ mouse hepatocytes, compared with siRNA-control transfected cells (Fig. 3a). Still, PTEN and PDCD4 inhibition had little impact on TNF- $\alpha / \mathrm{CHX} / \mathrm{zVAD}$-fmk-induced cytotoxicity (Fig. 3b). Conversely, CDK2AP1 siRNA transfected hepatocytes displayed a reduction in CDK2AP1 total protein and mRNA levels $(p<0.01$; Fig. $3 \mathrm{c})$, which was associated with exacerbation of TNF- $\alpha / \mathrm{CHX} / \mathrm{zVAD}$ fmk-induced cell death in $m i R-21^{-1-}$ mouse hepatocytes ( $p$ $<0.05$; Fig. 3d). In agreement, after CDK2AP1 silencing, TNF- $\alpha / C H X / z V A D-f m k$-induced MLKL phosphorylation increased in $m i R-21^{-l-}$ mouse hepatocytes $(p<0.05)$, whereas little effects were observed in WT (Fig. 3e). Of note, $m i R-21^{-1-}$ mouse hepatocytes displayed increased CDK2AP1 protein levels compared with WT, while mRNA levels of CDK2AP1 were not affected (Fig. 3c). To confirm CDK2AP1 as a direct miR-21 target in primary mouse hepatocytes, cells were co-transfected with a luciferase reporter construct containing the miR-21 binding site within the CDK2AP1 3' untranslated region (UTR), or a negative control vector, and pre-miR-21/pre-miR-Control; CDK2AP1/Control siRNAs; or anti-miR-21/anti-miR-Control. Reporter luciferase activity decreased significantly after miR-21 overexpression $(p<0.05)$ and CDK2AP1 silencing $(p<0.01)$, slightly increasing upon transfection with antimiR-21 (Fig. 3f). Collectively, these results suggest that miR-21 silencing protects primary mouse hepatocytes from necroptosis, at least in part, by relief of CDK2AP1 repression.

\section{miR-21 is overexpressed in the liver of PBC patients and BDL mice, and miR-21 ablation ameliorates liver injury in BDL mice}

The fact that mir-21 regulates necroptosis in hepatocytes in vitro prompted us to further explore its role in the pathogenesis of cholestasis, where necroptosis is a prominent event [8]. miR-21 expression was $~ 30$-fold increased in the liver of $\mathrm{PBC}$ patients compared with normal controls ( $p<0.05$; Fig. 4a). Further, WT or $m i R-21^{-1-}$ C57BL/6 mice were subjected to sham surgery or BDL, and assessed at days 3 (acute injury) and 14 (chronic injury) post-surgery. miR-21 expression was increased in the liver of BDL mice at both time-points, compared with sham (at least, $p<0.05$; 
A
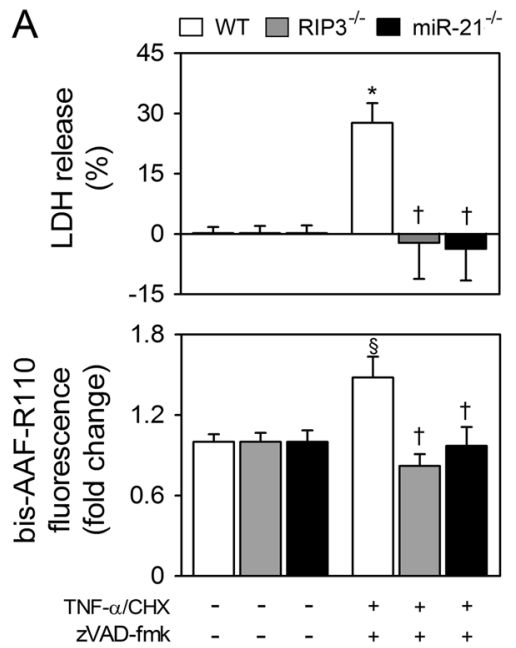

C
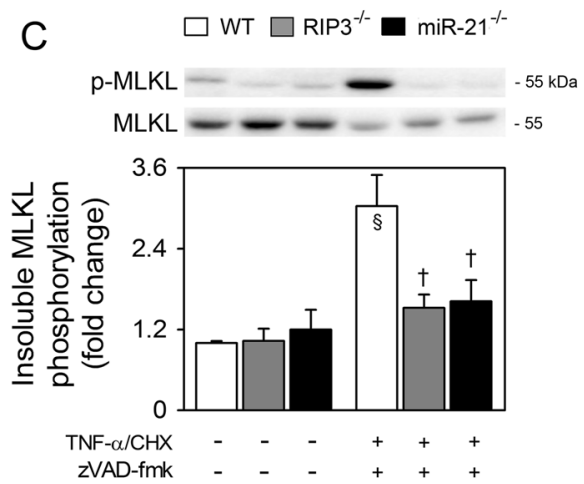

D

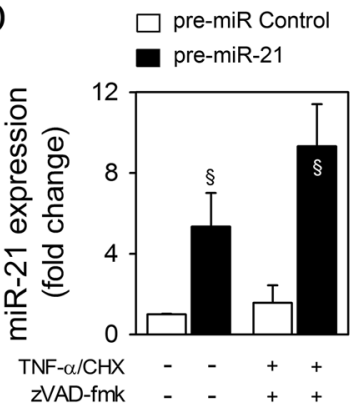

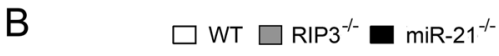
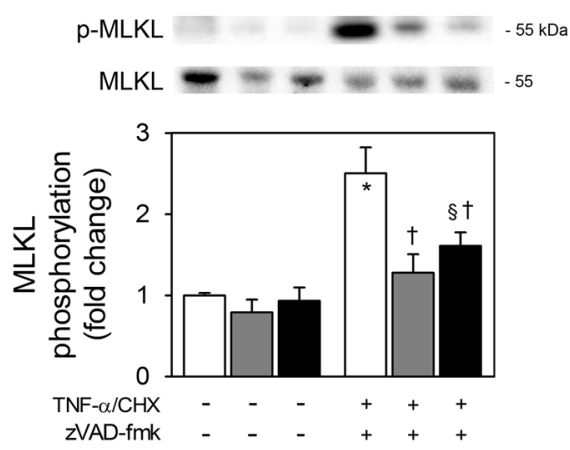

$\square \mathrm{WT} \square \mathrm{RIP}^{-1-} \square \mathrm{miR}-21^{-1-}$

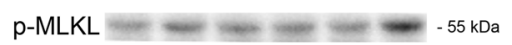

MLKL ----55

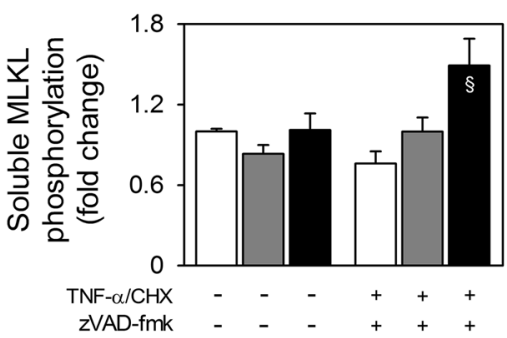

E

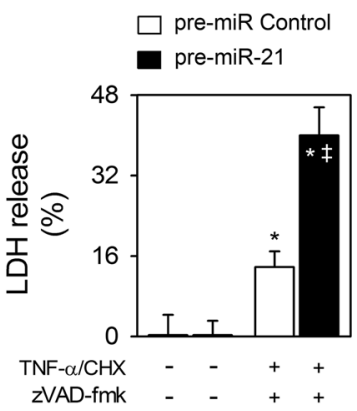

$\mathrm{F}$ p-MLKL - $-55 \mathrm{kDa}$ MLKL --55

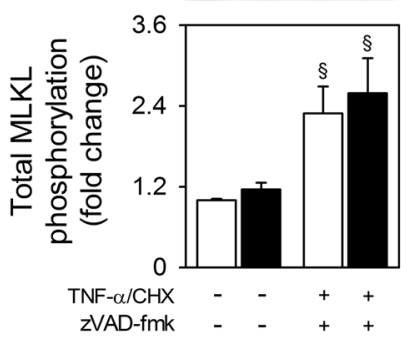

$\square$ pre-miR Control pre-miR-21

$-55 \mathrm{kDa}$ $--5=-5$

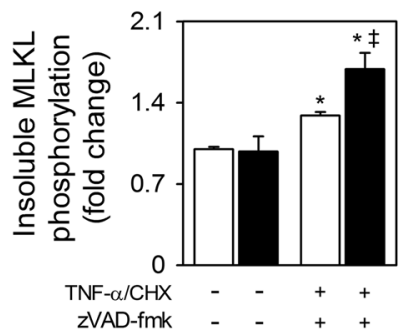

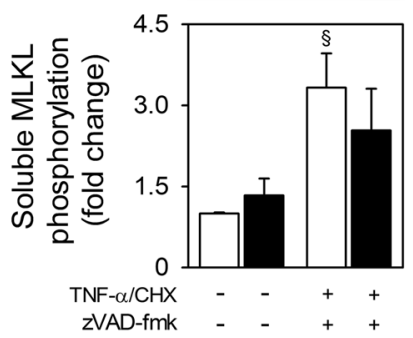

Fig. 4b). As expected, BDL in WT mice markedly increased serum levels of both alanine transaminase (ALT) and alkaline phosphatase (AP) (at least, $p<0.05$ ). BDL in $m i R$ -
$21^{-1-}$ resulted in reduced circulating levels of hepatic enzymes compared with WT mice at both 3 and 14 days ( $p$ $<0.05$; Fig. 4c). 
Fig. 1 miR-21 modulates necroptosis in primary mouse hepatocytes. Primary mouse hepatocytes isolated from WT, Rip $3^{-/-}$, and $m i R-21^{-1-}$ C57BL/6 mice were treated with TNF- $\alpha(10 \mathrm{ng} / \mathrm{mL}) / \mathrm{CHX}(0.5 \mu \mathrm{g} /$ $\mathrm{mL}) / \mathrm{zVAD}$-fmk $(50 \mu \mathrm{M})$ or vehicle control. After $36 \mathrm{~h}$, cells were harvested for cell death assays and protein extraction. a. General cell death in primary mouse hepatocytes as assessed by the percentage of LDH release assay (top) or bis-AAF-R110 fluorescence (bottom). Immunoblotting and densitometry of p-MLKL and MLKL in whole cells extracts (b) and in insoluble and soluble protein fraction (c). Blots of p-MLKL were normalized to MLKL. Representative immunoblots are shown. $\mathbf{d}$. WT primary mouse hepatocytes were transfected with a miR-21 precursor (pre-miR-21) or control (pre-miR-Control) for $16 \mathrm{~h}$ as described in Materials and Methods, and then loaded with TNF- $\alpha /$ $\mathrm{CHX} / \mathrm{zVAD}$-fmk or vehicle control for $28 \mathrm{~h}$. qRT-PCR analysis of $m i R-21$. e. Percentage of general cell death as assessed by LDH release. f. Immunoblotting and densitometry of p-MLKL and MLKL in whole cell extracts (left), insoluble protein fraction (middle) and soluble protein fraction (right). Blots of p-MLKL were normalized to MLKL. Representative immunoblots are shown. Results are expressed as mean \pm S.E.M. fold change or percentage from 3-5 independent cultures from each genotype. ${ }^{\S} p<0.05$ and $* p<0.01$ from control; ${ }^{\dagger} p$ $<0.05$ and ${ }^{\ddagger} p<0.01$ from respective control
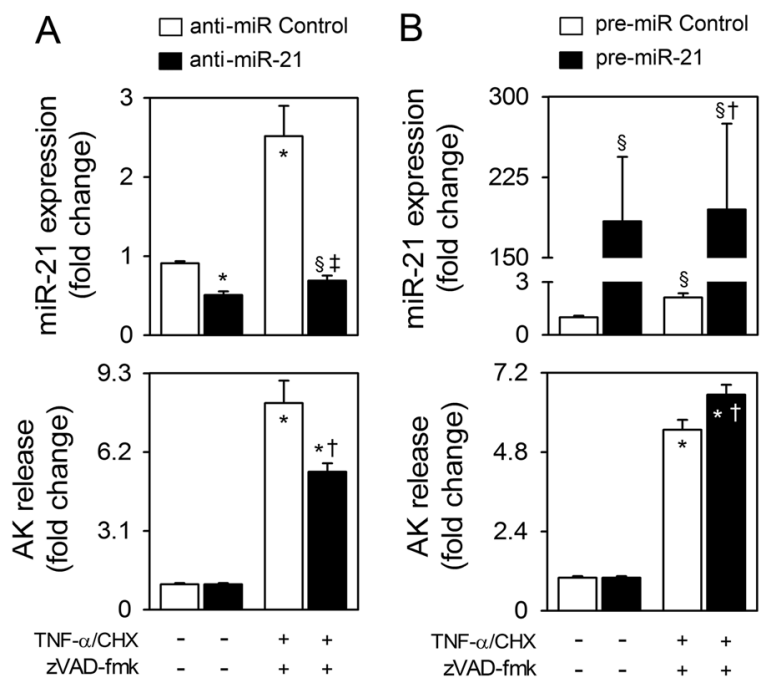

Fig. 2 miR-21 modulates necroptosis in L929 cells. a. L929 cells were transfected with a miR-21 specific inhibitor (anti-miR-21) or control (anti-miR-Control) for $24 \mathrm{~h}$ as described in Materials and Methods, and then loaded with TNF- $\alpha(10 \mathrm{ng} / \mathrm{mL})$ or vehicle control for $7 \mathrm{~h}$. qRT-PCR analysis of $m i R-21$ (top). Percentage of general cell death as assessed by AK release (bottom). b. L929 cells were transfected with a miR-21 precursor (pre-miR-21) or control (pre-miR-Control) for $24 \mathrm{~h}$ as described in Materials and Methods, and then loaded with TNF- $\alpha$ $(10 \mathrm{ng} / \mathrm{mL})$ or vehicle control for $7 \mathrm{~h}$. qRT-PCR analysis of $m i R-21$ (top). Percentage of general cell death as assessed by AK release (bottom)

Histopathological examination of liver specimens from 3-day BDL WT mice showed moderate to severe multifocal necrosis, accompanied by hemorrhage and inflammatory cell infiltration, which increased in severity at 14 days after BDL (Fig. 4d). In turn, $m i R-21^{-1-}$ mice displayed reduced BDL-induced hepatocellular degeneration $(p<0.05)$
(Fig. 4e). However, $m i R-21^{-1-}$ mice were not protected from hepatic inflammatory cell infiltration in response to BDL (Fig. 4d). Further, although pro-inflammatory cytokine macrophage inflammatory protein 2 (Mip-2) mRNA expression was reduced at both 3 and 14 days $(p<0.05)$, interleukin-1 $\beta \quad(I l-1 \beta)$ and toll-like receptor 4 (Tlr4) remained largely unchanged (Fig. 4f). Our results indicate that miR-21 is up-regulated in liver of PBC patients and BDL mice. Further, miR-21 deletion prevents BDL-induced liver damage.

\section{Deletion of miR-21 modulates hepatic fibrosis and apoptosis in BDL mice}

Previous studies have shown that miR-21 contributes to hepatic fibrogenesis in mice under a high fat diet or subjected to BDL for 7 days through inhibition of mothers against decapentaplegic homolog 7 (Smad-7)/transforming growth factor (TGF- $\beta$ ) pathway $[16,19]$. We show that $m i R$ $21^{-l-}$ mice displayed decreased mRNA levels of TGF- $\beta$ in sham and at day 3 post-BDL, comparing with WT mice (at least, $p<0.05$; Fig. 5a). In addition, mRNA levels of $\alpha$ smooth muscle actin $(\alpha-S m a)$, a cardinal marker for hepatic stellate cell activation, and collagen $1 \alpha 1$, were strongly increased in the liver of BDL WT mice at both 3 and 14 days compared with sham (at least, $p<0.05$ ). Conversely, mRNA levels of $\alpha$-Sma and collagen $1 \alpha 1$ were significantly reduced in BDL $m i R-21^{-1-}$ mice at both timepoints $(p<0.05$; Fig. 5a). Accordingly, hydroxyproline, a biochemical surrogate of collagen content was reduced in BDL miR-21 deficient mice ( $p<0.05$; Fig. 5b). Altogether, these results expand the knowledge on the mechanistic effects of miR-21 in regulating liver fibrosis.

Because caspase inhibition has been shown to attenuate fibrosis in BDL mice [21], we next ascertained whether miR-21 deficiency could modulate apoptosis. Following BDL, caspase- 3 and -8 were activated in the liver of BDL WT mice compared with sham at both 3 and 14 days, as assessed by immunoblotting of cleaved caspase-3 $(p<0.01$; Fig. 5c) and by enzymatic assays of caspase- 3 and -8 (at least, $p<0.05$; Fig. 5d). In turn, miR-21-deficiency reduced activation of caspase- 3 at day 3 post-BDL $(p<0.05)$, compared with BDL WT mice (Fig. 5c, d). Noteworthy, sham $m i R-21^{-I-}$ mice displayed increased caspase- 3 and -8 activities compared with WT mice (at least, $p<0.05$; Fig. $5 \mathrm{c}, \mathrm{d})$. Similar results were obtained when analyzing c-Jun N-terminal kinases (JNK) phosphorylation (Fig. 5e), which plays a key role in activating hepatocyte apoptosis and in engaging hepatic stellate cells and liver fibrogenesis in the BDL murine model [22]. Curiously, miR-21 deficiency had no impact on the number of terminal deoxynucleotidyl transferase dUTP nick end labeling (TUNEL)-positive cells in sham mice and 14 days after BDL, while $m i R-21^{-I-}$ mice 
Fig. 3 Deletion of miR-21 protects primary mouse hepatocytes from necroptosis via CDK2AP1. Primary hepatocytes isolated from WT and $m i R-21^{-1-}$ mice were transfected for $16 \mathrm{~h}$ with a siRNA targeting either PTEN (siPTEN), PDCD4 (siPDCD4), CDK2AP1 (siCDK2AP1) or a scrambled control (siControl), as described in Materials and Methods, and then loaded with TNF- $\alpha / \mathrm{CHX} / \mathrm{zVAD}$-fmk or vehicle control for $28 \mathrm{~h}$. a. Representative immunoblots of PTEN and PDCD4. $\beta$-actin was used as a loading control. b. Percentage of cell death as assessed by LDH release in hepatocytes incubated with TNF- $\alpha / \mathrm{CHX} / z V A D-f m k$. c. Representative immunoblots of CDK2AP1. $\beta$-actin was used as a loading control (top). qRT-PCR analysis of CDK2AP1 (bottom). d. Percentage of cell death as assessed by LDH release. e. Immunoblotting and densitometry of p-MLKL and MLKL in whole cells extracts. Blots of p-MLKL were normalized to MLKL.

Representative immunoblots are shown. f. Hepatocytes isolated from WT mice were cotransfected with a CDK2AP1 luciferase reporter vector, or negative control, and pre-miR21/pre-miR-Control; CDK2AP1/ Control siRNAs; or anti-miR-21/ anti-miR-Control for $24 \mathrm{~h}$. Renilla luciferase signal was used as an internal standard control. Results are expressed as mean \pm S.E.M. fold change or percentage of 3-5 independent cultures from each genotype. ${ }^{\S} p$ $<0.05$ and $* p<0.01$ from control; ${ }^{\dagger} p<0.05$ and ${ }^{\ddagger} p<0.01$ from respective control
A

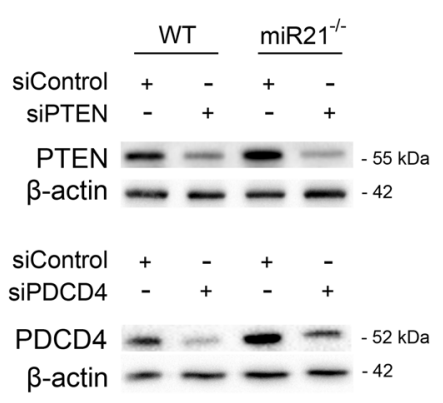

C
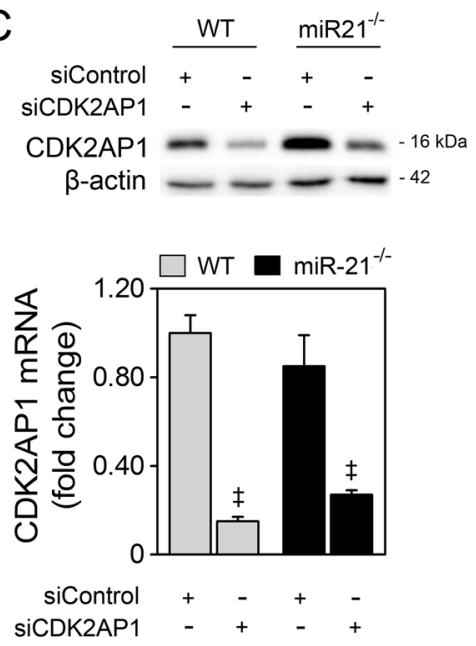

B
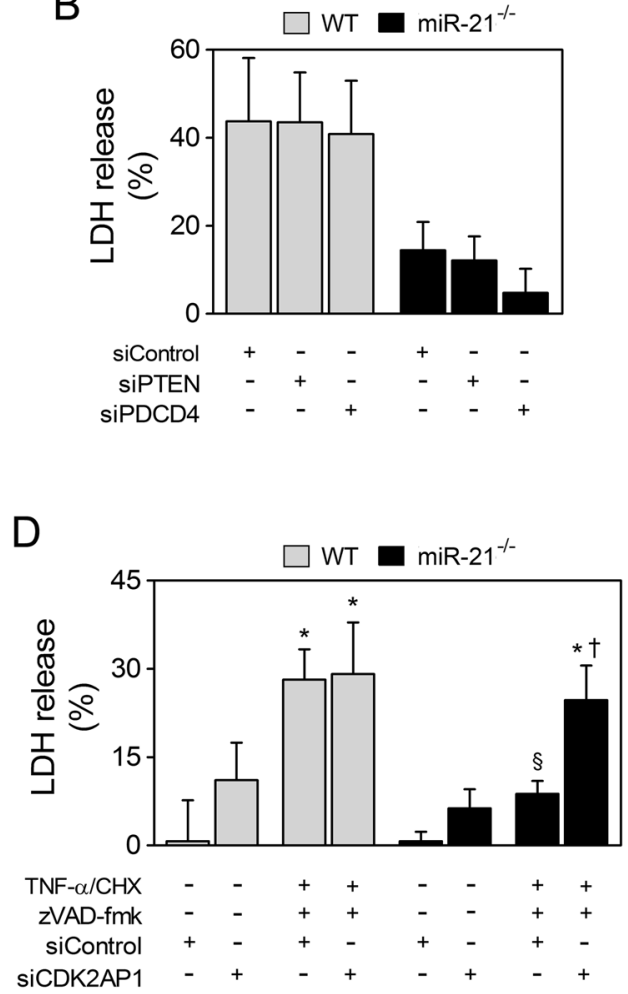

E
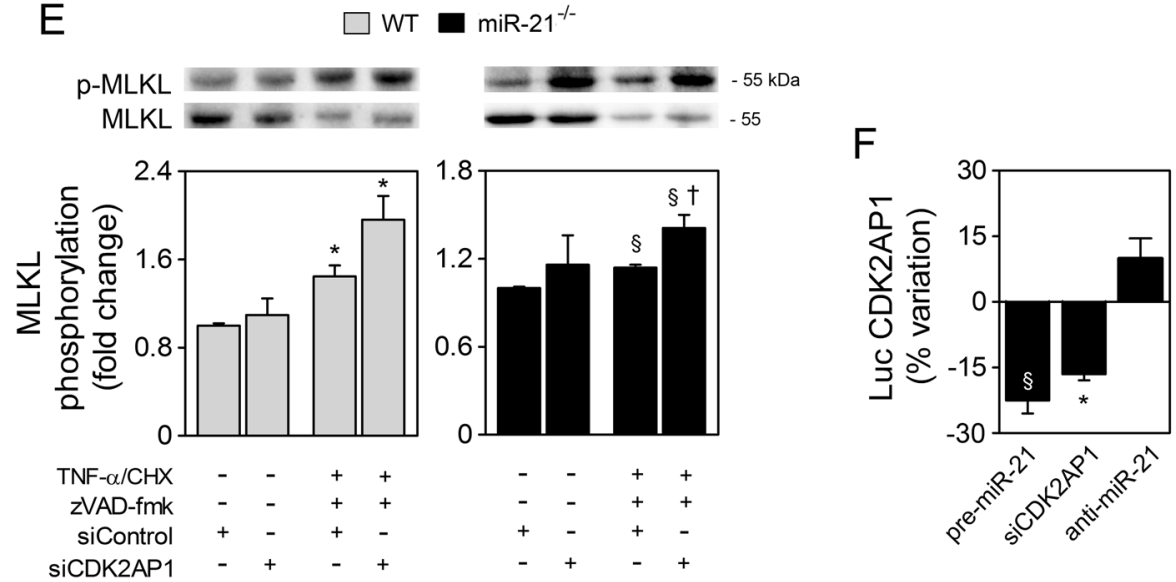

displayed decreased TUNEL-positive cells at day 3 postBDL, compared with WT mice ( $p<0.05$; Fig. 5f). These data suggest that apoptosis is not increased in the liver of $m i R-21^{-1-}$ mice, with deletion of miR-21 even protecting from BDL-induced apoptosis at day 3. In agreement, we and others have reported that $m i R-21^{-1-}$ mice do not exhibit liver phenotypic alterations and are protected from apoptosis in non-alcoholic fatty liver disease murine models $[17,18,23]$. As such, increased caspase-3/-8 activation and JNK phosphorylation in sham $m i R-21^{-1-}$ mice are likely an adaptive response to surgery.

\section{Ablation of miR-21 prevents necroptosis in the liver of BDL mice}

We have previously shown that BDL-induced necrotic cell death is, at least in part, necroptosis [8]. As such, we next evaluated whether deletion of miR-21 would also impinge on hallmarks of necroptosis in mice. $m i R-21^{-l-}$ showed decreased BDL-induced mRNA expression of RIP3 and MLKL at day 3 (at least, $p<0.05$; Fig. 6a). Similarly, in whole liver extracts, BDL favored the p-MLKL/MLKL ratio compared with WT mice (at least, $p<0.01$ ), while 


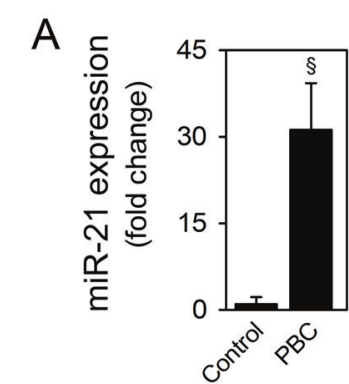

D

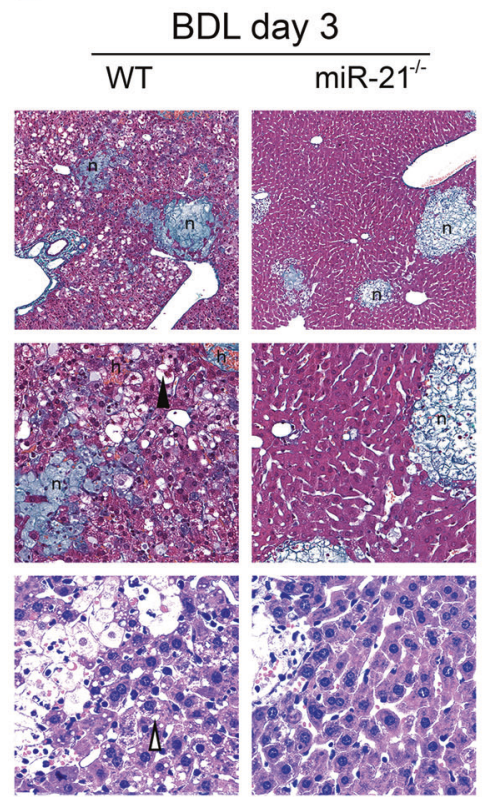

B

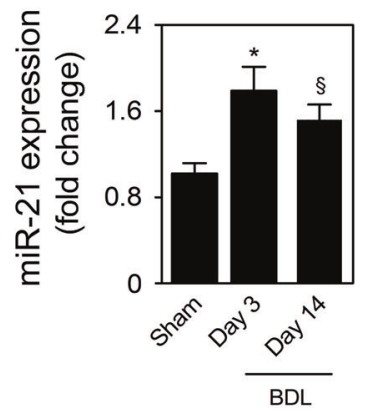

C
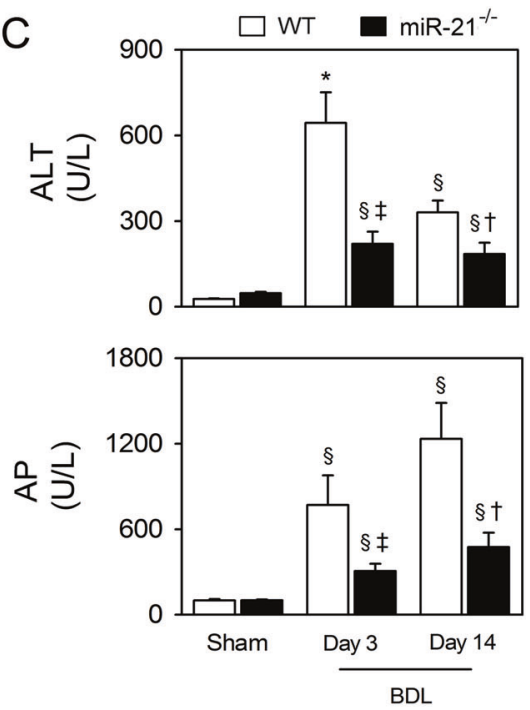

E

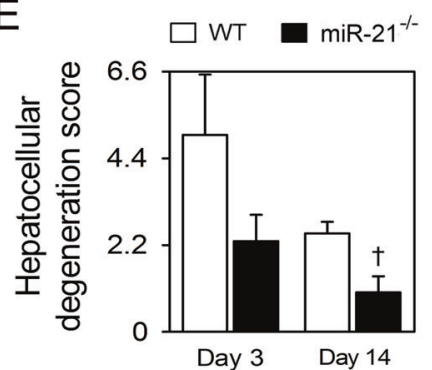

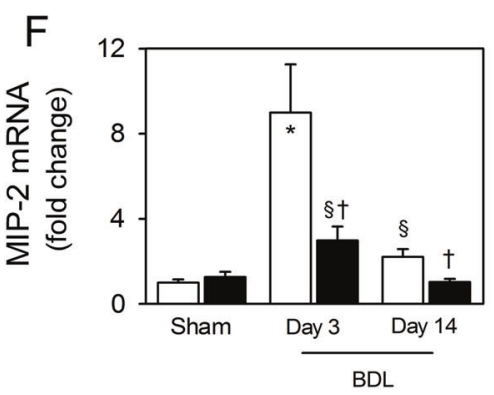

Fig. $4 \mathrm{miR}-21$ is overexpressed in the liver of PBC patients and BDL mice and ablation of miR-21 ameliorates liver injury in BDL mice. a. qRT-PCR analysis of miR-21 in the liver of 10 healthy controls and 5 PBC patients. Results are expressed as mean \pm S.E.M. fold change. $\mathbf{b}$. C57BL/6 WT and $m i R-21^{-1-}$ mice were subjected to sham or BDL surgical procedures and euthanized at days 3 and 14. qRT-PCR analysis of miR-21. miR-21 expression was not detected in $m i R-21^{-1-}$ mice. c. Serum ALT and AP levels. d. Representative images of H\&E or Masson's Trichrome stained liver sections. $n$, necrosis; $h$, hemorrhage; black arrowhead, hydropic degeneration; white arrowhead, cytoplasmic changes characterized by increased cytoplasmic granularity, cell swelling, and eosinophilia. e. Hepatocellular degeneration, scored as described in Materials and Methods. f. qRT-PCR analysis of Mip-2, Il-1 $\beta$ and Tlr4 in mouse liver. Results are expressed as mean \pm S.E.M. arbitrary units or fold change of 4-7 individual mice. ${ }^{\S} p<0.05$ and $* p<0.01$ from sham-operated mice; ${ }^{\dagger} p<0.05$ and ${ }^{\ddagger} p<0.01$ from BDL WT mice at respective time-point
MLKL phosphorylation was decreased in $m i R-21^{-1-}$ mice at day 3 post-BDL $(p<0.05$; Fig. 6b). Intriguingly, although sham $m i R-21^{-1-}$ mice did not display increased hepatic mRNA and protein levels of RIP3 compared with sham WT mice (Figs. 6a, b), MLKL phosphorylation was increased $(p<0.05$; Fig. 6b). Again, because sham $m i R-21^{-1-}$ mice do not display increased liver injury, it is likely that MLKL phosphorylation does not correlate with 
A
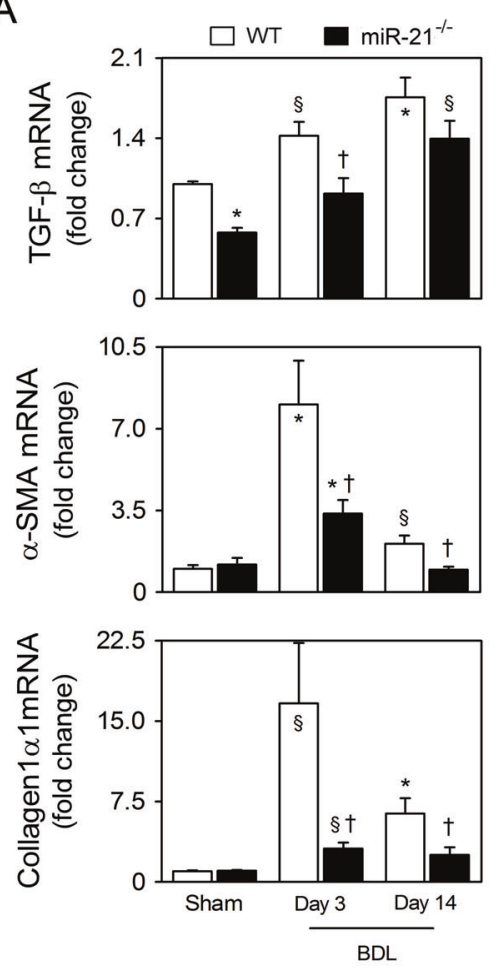

B

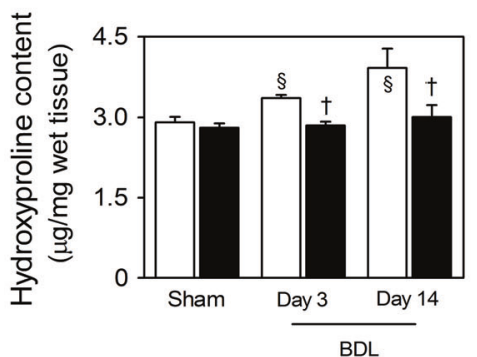

E

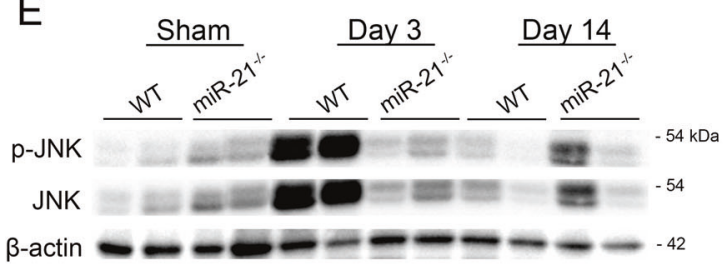

C

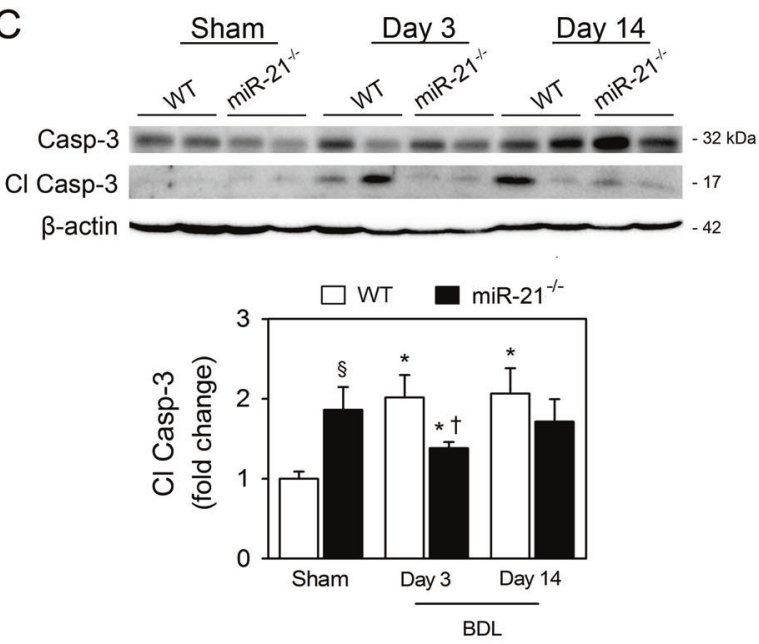

D
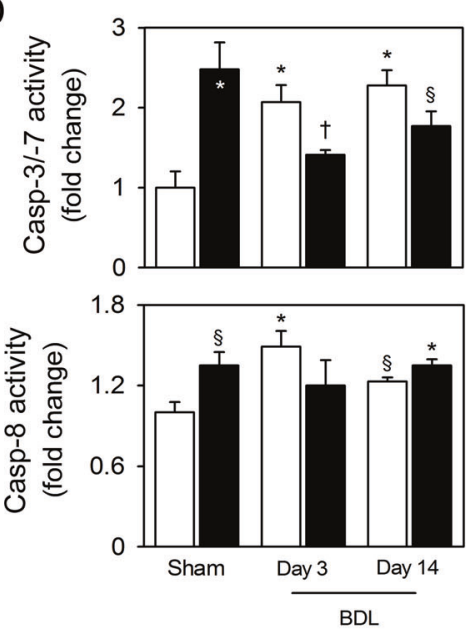

$\mathrm{F}$
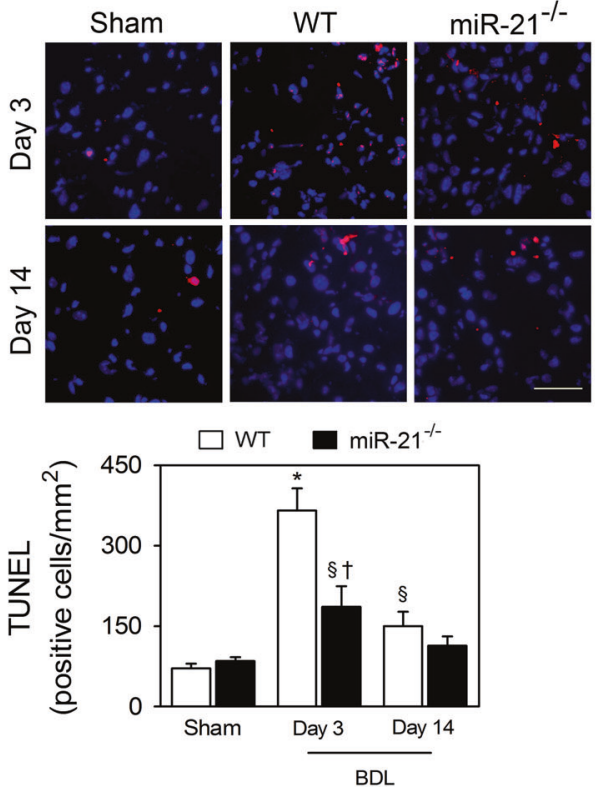

protected from liver necroptosis at this time-point, as the phosphorylated MLKL levels are similar to baseline for this genotype (Fig. 6b). To test this hypothesis, we next necroptosis. This would also imply that, although MLKL phosphorylation levels are similar between $m i R-21^{-1-}$ and WT mice at day 14 post-BDL, $m i R-21^{-1-}$ mice were also 
Fig. 5 miR-21 ablation decreases hepatic fibrogenic and apoptosis markers in response to BDL. C57BL/6 WT and $m i R-21^{-1-}$ mice were subjected to sham or BDL surgical procedures and euthanized at days 3 and 14. a. qRT-PCR analysis of Tgf- $\beta, \alpha-S m a$ and collagen $1 \mathrm{a} 1$ in mouse liver. b. Liver hydroxyproline content. c. Immunoblotting and densitometry of caspase-3 in whole liver extracts. Blots were normalized to endogenous $\beta$-actin. Representative immunoblots are shown. d. Caspase-3/7 and -8 enzymatic activities. e. Immunoblotting and densitometry of p-JNK and JNK in whole liver extracts. Blots of p-JNK were normalized to JNK. Representative immunoblots are shown. f. TUNEL staining of liver tissue sections (red). Nuclei were counterstained with Hoechst 33258 (blue). Scale bar, $50 \mu \mathrm{m}$. Histogram shows the quantification of TUNEL-positive cells $/ \mathrm{mm}^{2}$. Results are expressed as mean \pm SEM fold change of 5-7 individual mice. ${ }^{\S} p$ $<0.05$ and $* p<0.01$ from sham-operated mice; ${ }^{\dagger} p<0.05$ from BDL WT mice at respective time-point. Casp-3/-7/-8, caspase-3/-7/-8; Cl Casp-3, cleaved caspase-3

evaluated expression levels of RIP3 and MLKL in soluble/ insoluble protein fractions of BDL livers. Indeed, RIP3 and p-MLKL were preferentially retained in the insoluble protein fraction of BDL WT mice, compared with sham, at both time-points (at least, $p<0.05$; Fig. 6c). In turn, as previously shown for $\operatorname{Rip}^{-/-}$mice [8], miR-21-deficiency prevented sequestration of RIP3 and p-MLKL in the insoluble protein fraction of the liver at both 3 and 14 days (at least, $p<0.05$ ). Further, sham and 14-day BDL $m i R-21^{-1-}$ mice displayed increased levels of MLKL phosphorylation in the soluble protein fraction (at least, $p<0.05$; Fig. 6c). Therefore, most of the p-MLKL detected in the liver of $m i R-21^{-1-}$ mice was retained in the soluble protein fraction of the liver, suggesting that p-MLKL was not in an oligomeric conformation for necroptosis execution. Noteworthy, corroborating the in vitro data, sham and BDL $m i R-21^{-1-}$ mice displayed increased CDK2AP1 protein levels in whole liver extracts compared with WT mice $(p<0.05$; Fig. $6 \mathrm{~b})$, while mRNA levels of CDK2AP1 were not significantly affected (data not shown). These findings further reinforce the post-transcriptional modulation of CDK2AP1 by miR21 and its functional role in protecting from necroptosis. Overall, our results suggest that miR-21 impairs activation of necroptosis in the liver of BDL mice, likely through CDK2AP1 targeting.

\section{miR-21-deficiency ameliorates oxidative stress during BDL acute phase}

We previously reported that inhibition of necroptosis in Rip $3^{-l-}$ male mice subjected to BDL was associated with increased hepatic heme oxygenase-1 (HO-1) expression and consequent iron accumulation [8]. In this study, BDL WT mice displayed a significant increase in HO-1 mRNA levels at day $3(p<0.05)$. In turn, miR-21-deficiency decreased expression of HO-1 at day 3 post-BDL $(p<0.05$; Fig. 7a). Accordingly, because iron is a product of heme catabolism by HO-1, deletion of miR-21 decreased the amount of labile iron in the liver of BDL mice at day 3 post-BDL $(p<0.05$; Fig. 7b). Finally, lipid peroxidation and reactive oxygen species (ROS) generation were significantly increased in the liver of BDL WT mice compared with sham WT mice at both time-points (at least, $p<0.05$ ). In turn, BDL $m i R-21^{-1-}$ mice displayed significantly lower levels of ROS and lipid peroxidation, most notably at day 3 (at least, $p<$ 0.05), comparing with BDL WT mice (Fig. 7c). Collectively, BDL-induced HO-1 expression and iron accumulation were prevented in $m i R-21^{-1-}$ mice. In addition, the absence of miR-21 further decreased BDL-associated oxidative stress, particularly at early stages.

\section{miR-21 $1^{-1-}$ mice display improved bile acid adaptive response after $\mathrm{BDL}$}

We next assessed the functional role of miR-21 in the adaptive response of genes coding for the nuclear receptors farnesoid $\mathrm{x}$ receptor $(F x r)$, pregnane $\mathrm{x}$ receptor $(P x r)$ and liver $\mathrm{x}$ receptor $(L x r)$, given their beneficial effects on bile acid metabolism and protection against liver damage [2426]. $m i r-21^{-1-}$ mice displayed increased mRNA levels of $F x r$ and $P x r$ in the liver, both under basal conditions and after BDL (at least, $p<0.05$; Fig. 8a). Likewise, although sham $m i R-21^{-1-}$ mice displayed decreased $L x r$ mRNA levels in the liver compared with sham WT mice, $L x r$ mRNA expression was higher in $m i R-21^{-1-}$ mice when compared to WT mice following BDL $(p<0.05$; Fig. 8a). As expected, BDL also led to reduced cytochrome P450 family 7 subfamily A member 1 (Cyp7al) expression in WT mice $(p<0.05)$ and, despite higher mRNA levels of Cyp7al in $m i R-21^{-1-}$ than in WT mice following BDL $(p<0.05)$, Cyp7al was reduced in both sham and BDL $m i R-21^{-l-}$ mice, compared with sham WT mice $(p<0.05$; Fig. 8 b). Moreover, $m i R-21^{-1-}$ mice also displayed higher expression levels of sulfotransferase family $2 \mathrm{~A}$ member 1 (Sult2a1) $(p<0.05$; Fig. $8 b)$, a phase II bile aciddetoxifying enzyme. In WT mice, expression of the basolateral bile acid uptake organic anion-transporting polypeptide (Oatp) and sodium/taurocholate co-transporting polypeptide (Ntcp) were reduced in the liver at day 3 postBDL $(p<0.05)$, remaining unchanged at day 14 . In contrast, $m i R-21^{-l-}$ mice also displayed increased levels of Oatp in both sham and BDL mice, as well as of Ntcp at day 3 post-BDL, comparing with sham WT mice (at least, $p<$ 0.05; Fig. 8c). Finally, following BDL, deletion of miR-21 was associated with an increase in basolateral efflux transporter multispecific organic anion transporter $2(\mathrm{Mrp} 3)$ and bile salt export pump (Bsep), compared with WT mice (at least, $p<0.05$; Fig. 8d). Altogether, miR-21-deficiency associates with increased mRNA expression of uptake, detoxification, efflux and bile acid biosynthesis genes, 
A

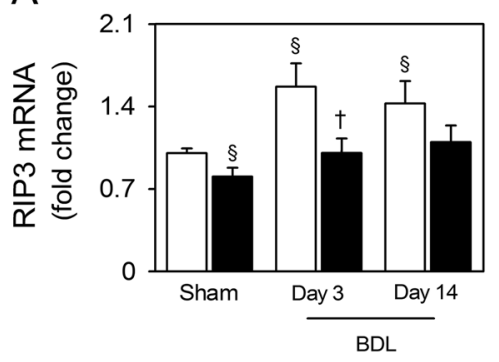

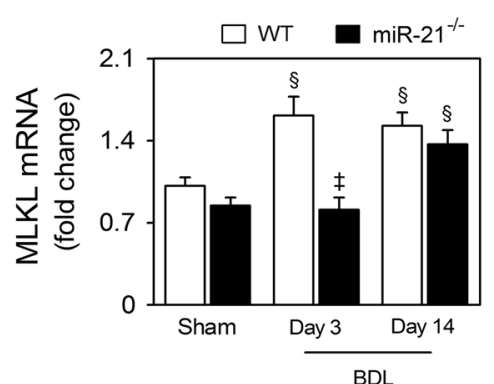

Day 3 Day 14
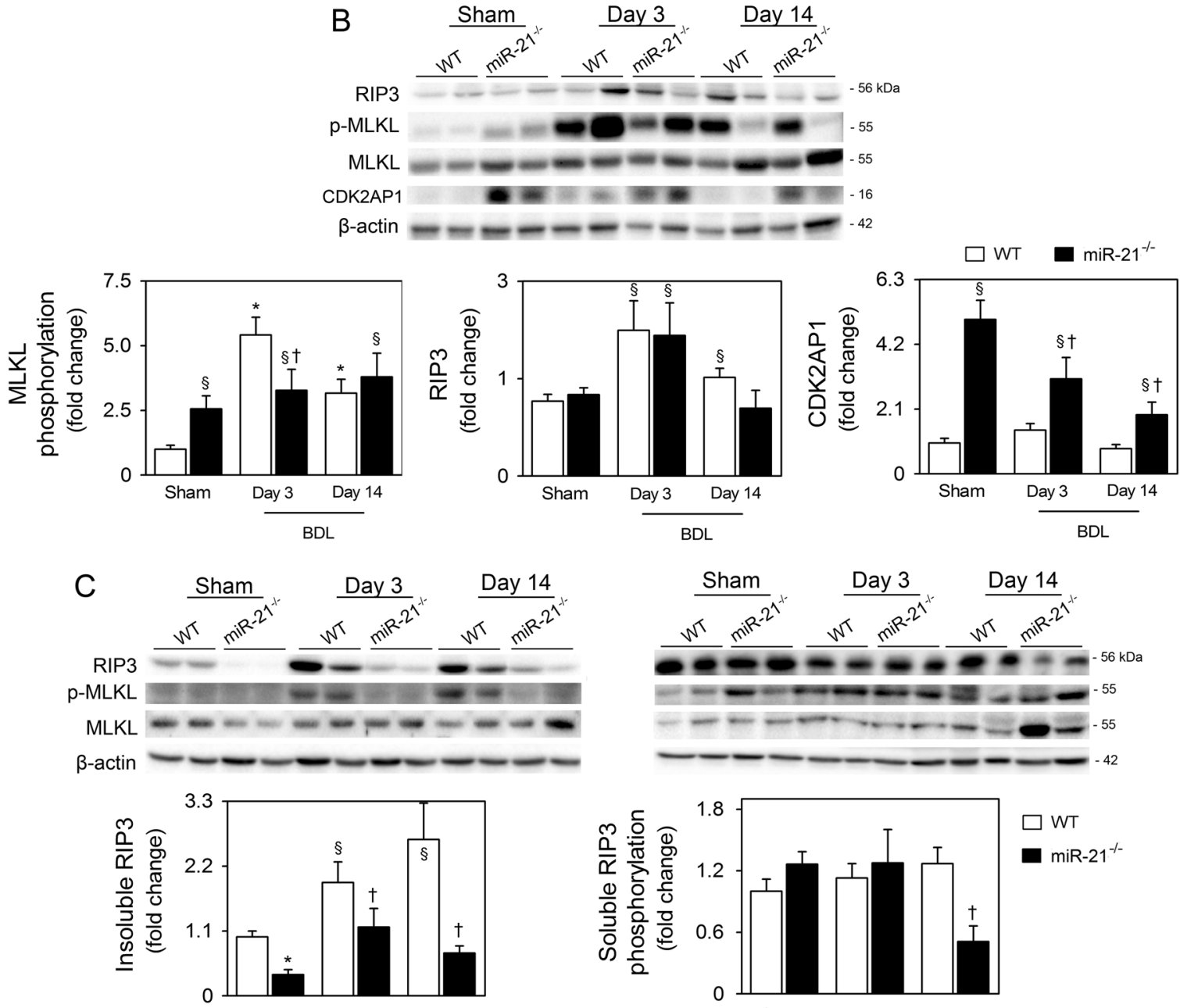

$\square \mathrm{WT}$

miR-21 $1-$
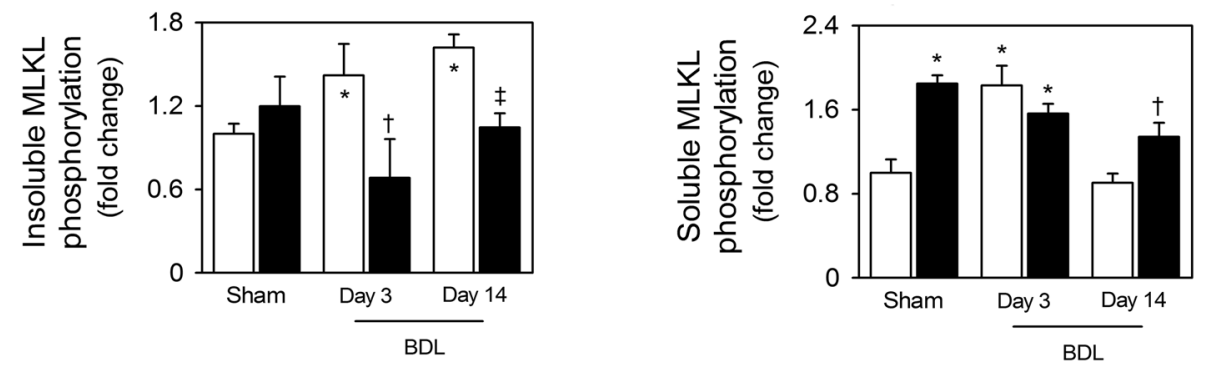

Fig. 6 Ablation of miR-21 prevents necroptosis in the BDL mice liver. $\mathrm{C} 57 \mathrm{BL} / 6 \mathrm{WT}$ and $m i R-21^{-I-}$ mice were subjected to sham or BDL surgical procedures and euthanized at days 3 and 14. a. qRT-PCR analysis of RIP3 and MLKL in mouse liver. Immunoblotting and densitometry of RIP3, p-MLKL, MLKL, and CDK2AP1 in whole liver extracts (b) and RIP3, p-MLKL, and MLKL in insoluble and

soluble protein fractions (c). Blots of RIP3 and CDK2AP1 were normalized to endogenous $\beta$-actin, whereas p-MLKL was normalized to MLKL. Representative immunoblots are shown. Results are expressed as mean \pm S.E.M. fold change of 5-7 individual mice. ${ }^{\S} p<$ 0.05 and $*^{*} p<0.01$ from sham-operated mice; ${ }^{\dagger} p<0.05$ and ${ }^{\ddagger} p<0.01$ from BDL WT mice at respective time-point 

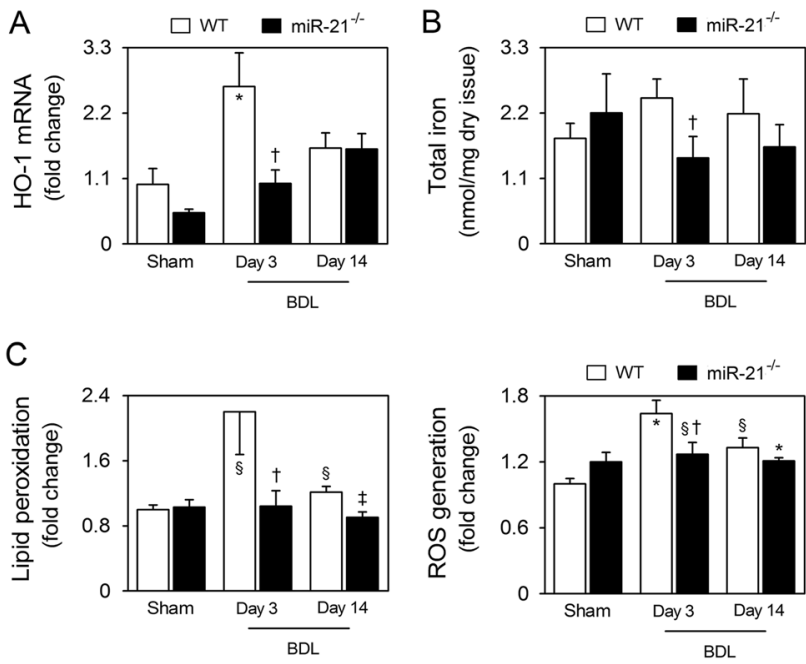

Fig. 7 Absence of miR-21 ameliorates oxidative stress during the acute phase of BDL. C57BL/6 WT and $m i R-21^{-/-}$mice were subjected to sham or BDL surgical procedures and euthanized at days 3 and 14. a. qRT-PCR analysis of HO-1 in mouse liver. Labile iron content (b), lipid peroxidation and ROS generation (c) were measured as described in Materials and Methods. Results are expressed as mean \pm SEM arbitrary units or fold change of 5-7 individual mice. ${ }^{\S} p<0.05$ and ${ }^{*} p<0.01$ from sham-operated mice; ${ }^{\dagger} p<0.05$ from BDL WT mice at respective time-point

suggesting that the absence of miR-21 elicits a robust adaptive response to decrease bile acid levels (Fig. 8e).

\section{Discussion}

miR-21 is up-regulated in human liver diseases, including in the serum of PBC patients [27]. In this study, we show that miR-21 is also overexpressed in the liver of PBC patients. In cholestatic liver diseases, miR-21 overexpression might result from changes in the composition of the bile acid pool in the liver. In fact, we previously showed that bile acids differentially modulate miR-21 expression in primary rat hepatocytes and after liver regeneration [28]. For instance, hepatic concentrations of deoxycholic acid (DCA) are strongly reduced in patients with end-stage chronic cholestasis compared with normal liver tissue [29], whereas DCA inhibits miR-21 expression in primary rat hepatocytes and in the rat liver [30]. The pathogenic effects of miR-21 overexpression involve unbalanced cell proliferation/apoptosis [15,31], impaired metabolic homeostasis $[17,18,23]$ and fibrogenesis $[16,18,19]$. Here, we demonstrate that miR-21 also regulates liver necroptosis. Because necroptosis is a common pathological feature of human and experimental liver disease [3,5-8,32], this discovery could shed new light on the prospective therapeutic targeting of miR-21 in hepatic disorders.

We have previously shown that necroptosis is triggered in the liver of PBC patients and that RIP3-dependent necroptosis mediates necro-inflammation during BDL- induced liver injury in mice [8]. Here, we focused on the role of miR-21 in regulating necroptosis during cholestatic liver injury and found that the histological pattern of protection against hepatocellular necrosis over time in BDL $m i R-21^{-I-}$ mice was similar to those previously demonstrated for Rip3-deficient mice [8]. In addition, despite the increased endogenous levels of MLKL phosphorylation, $m i R-21^{-1-}$ mice are protected from BDL-induced retention of RIP3 and MLKL in the insoluble protein fraction, suggesting a decrease in oligomerization, required for execution of necroptosis $[3,33]$. We also show that miR-21 overexpression further potentiates cell death upon a necroptotic stimulus in L929 cells and primary mouse hepatocytes, as reflected by increased sequestration of $\mathrm{p}$ MLKL in insoluble fractions, but not augmented MLKL phosphorylation in total proteins. This suggests that deletion of miR-21 could also halt MLKL oligomerization downstream of RIP3 activation. Similarly, heat shock protein 90 inhibitors prevent necroptosis downstream of MLKL activation by hampering oligomerization and membrane translocation [34]. Thus, RIP3 and p-MLKL in soluble/insoluble protein fractions is valuable in assessing the dynamics of necroptosis activation $[5,8,35]$, particularly when comparing different genotypes/cells with distinct necroptosis proteins at baseline [36]. Indeed, it was recently shown that MLKL phosphorylation alone may not commit a cell to die [37]. Of note, although increased in the liver of sham $m i R-21^{-1-}$ mice, MLKL phosphorylation was similar between primary mouse hepatocytes isolated from WT and $m i R-21^{-1-}$ mice. Thus, it is possible that non-parenchymal liver cells contribute to increased MLKL phosphorylation detected in the liver of $m i R-21^{-1-}$ mice under basal conditions. In this regard, we previously reported that RIP3 and p-MLKL are increased in hepatocytes and cells morphologically reassembling biliary epithelia in PBC patients [8]. Further, miR-21 is particularly overexpressed in biliary cells in human and experimental non-alcoholic steatohepatitis [17], as well as in BDL and $M d r 2$ knockout mice [19]. Hence, it is likely that miR-21 plays a critical role in modulating necroptosis in cholangiocytes during cholestasis. We also found that deletion of miR-21 provides a genetic adaptive response favoring hepatic clearance of bile acids, an effect that might be beneficial per se in a broad range of cholestatic liver diseases in which miR-21 is overexpressed $[19,20]$.

Reduction of immunogenic necroptosis in $m i R-21^{-1-}$ mice had no impact on hepatic inflammatory cell infiltration following BDL, in contrast to what we have previously reported in Rip $3^{-1-}$ mice [8]. This may be attributed to an inherent anti-inflammatory function of miR-21, which has been reported to negatively regulate TLR4 signaling via PDCD4 targeting in peripheral blood mononuclear cells and macrophages [38]. Curiously, here we show that $m i R-21^{-I-}$ 

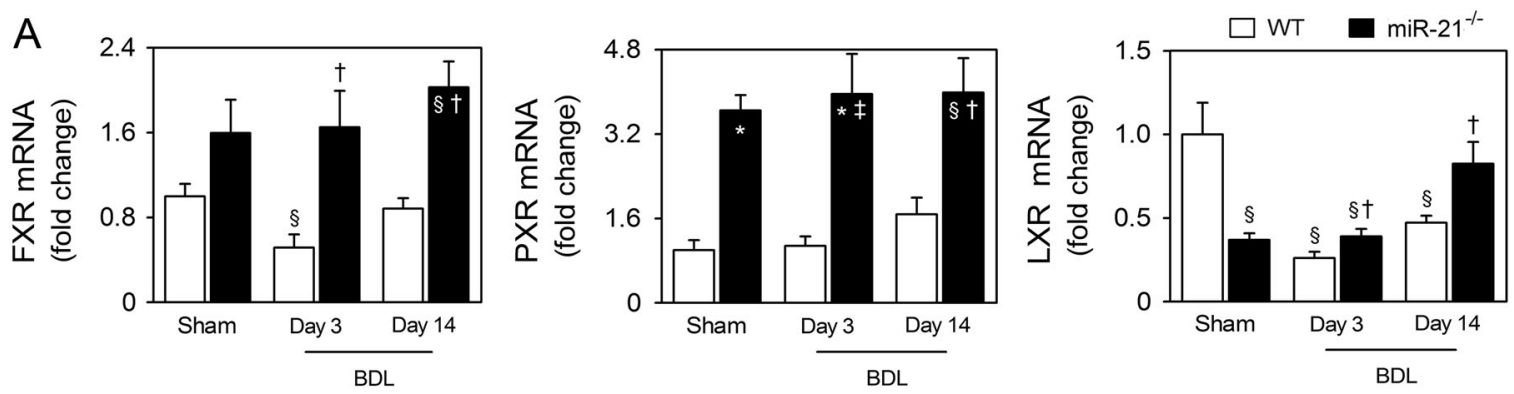

B
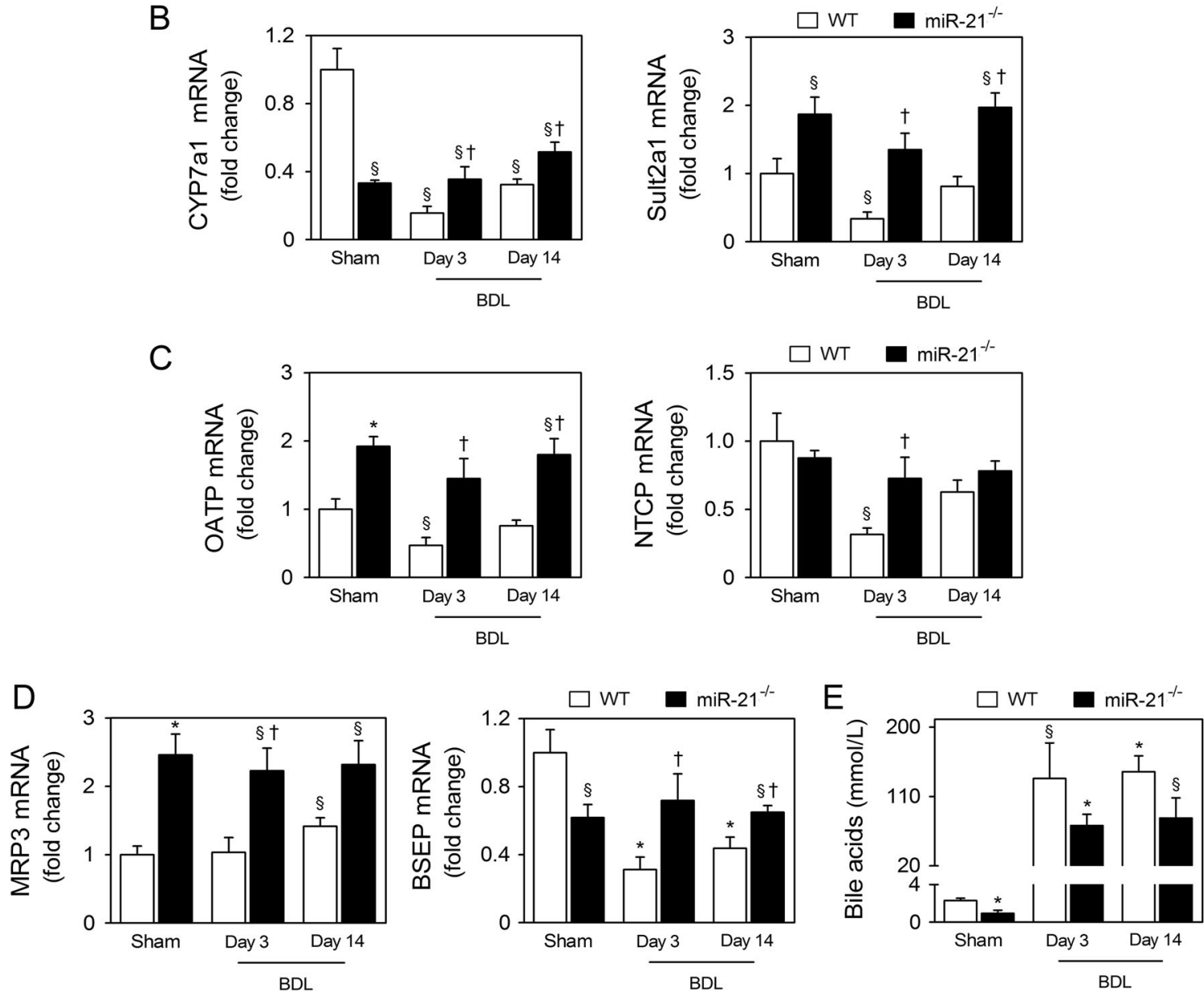

Fig. 8 miR-21 ablation provides an adaptive response in the expression of bile acid homeostasis-associated genes in response to BDL. $\mathrm{C} 57 \mathrm{BL} / 6 \mathrm{WT}$ and $m i R-21^{-1-}$ mice were subjected to sham or BDL surgical procedures and euthanized at days 3 and 14. qRT-PCR analysis of Fxr, Pxr and Lxr (a); Cyp7al and Sult2al (b); Oatp and Ntcp

mice display increased hepatic mRNA levels of TLR4 under basal conditions. Nevertheless, deletion of miR-21 may still impact the inflammatory response as suggested by diminished expression of MIP-2, a cytokine upregulated by bile acids in hepatocytes [39].

Very few studies have evaluated the regulation of necroptosis by miRNAs. Deletion of miR-21 protected mice with acute pancreatitis from necroptosis, likely due to (c); and Mrp3 and Bsep in mouse liver (d). e. Serum bile acid levels. Results are expressed as mean \pm SEM arbitrary units or fold change of 5-7 individual mice. ${ }^{\S} p<0.05$ and $* p<0.01$ from sham-operated mice; ${ }^{\dagger} p<0.05$ and ${ }^{\ddagger} p<0.01$ from BDL WT mice at respective timepoint

caspase-8 activation [13]. Our experiments highlighted CDK2AP1 as a critical player, which is a validated target of miR-21 acting as a growth suppressor master regulator of cell cycle [40]. Indeed, several proteins implicated in cell cycle regulation have been detected as hits in a necroptosis phenotypic screen using L929 cells [41], as well as in primary microglia from mice genetically susceptible to necroptosis [42]. Because a role for CDK2AP1 is emerging 


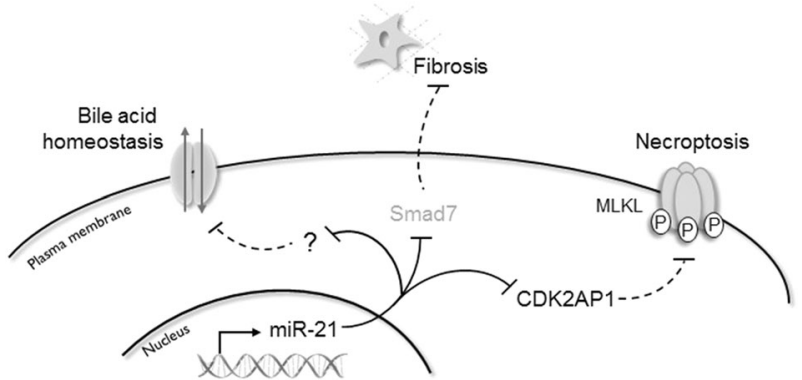

Fig. 9 Schematic model depicting the deleterious effects of increased miR-21 expression during cholestasis

in epigenetic regulation [43], it could also modulate RIP3, often silenced through promoter methylation in cancer cells [44]. In this study, absence of miR-21 reduced mRNA levels of RIP3, under basal conditions and at 3 days after BDL. Nevertheless, further investigation is required to dissect the specific role of CDK2AP1 in regulating necroptosis.

In conclusion, via functional studies, we show that deletion of miR-21 prevents activation of necroptosis in primary mouse hepatocytes, at least in part, through negative regulation of CDK2AP1 (Fig. 9). We also demonstrate that miR-21 is overexpressed in the liver of PBC patients and BDL mice. miR-21 ablation ameliorates liver damage and necroptosis, via CDK2AP1, and provides an improved adaptive response of bile acid homeostasis. Further, deletion of miR-21 protects from fibrosis and acute oxidative stress in the livers of BDL mice. As such, miR-21 is a novel and attractive target for therapeutic intervention in cholestatic liver disease.

\section{Materials and methods}

\section{Animal experiments}

BDL [10] was performed in 10-12 weeks old wild-type C57BL/6 female mice (WT) with 25-30 g (Charles River Laboratories International, Inc., Wilmington, MA, USA) or in RIP3-deficient mice (Rip ${ }^{-1-}$ ) [45], as previously described [8]. Controls underwent sham operation with exposure of the common bile duct but without ligation. Five to seven animals were included in each experimental group. Serum was collected and the liver removed; one lobe was collected, rinsed in normal saline and immediately flashfrozen in liquid nitrogen for protein and RNA extraction; the other lobe was fixed in paraformaldehyde $(4 \%, \mathrm{wt} / \mathrm{vol})$ in phosphate buffered saline (PBS; Thermo Fisher Scientific Inc., Waltham, MA, USA) for paraffin-embedded sectioning. All animal experiments were carried out with the permission of the local animal ethical committee in accordance with the EU Directive (2010/63/EU), Portuguese laws (DL 113/2013, 2880/2015, 260/2016) and all relevant legislations. The experimental protocol was approved by Direcção Geral de Alimentação e Veterinária. Animals received humane care in a temperature-controlled environment with a 12-h light-dark cycle, complying with the Institute's guidelines, and as outlined in the "Guide for the Care and Use of Laboratory Animals" prepared by the National Academy of Sciences and published by the National Institutes of Health (NIH publication 86-23 revised 1985).

\section{Patients}

Liver tissue was prospectively and sequentially collected from patients that fulfilled the clinical and pathological diagnostic features of PBC. All patients were on advance stage (stage IV). Liver biopsies from age and sex-matched controls were obtained from potential liver donors, with normal liver histology and biochemistry. All liver specimens were fixed, processed for routine diagnosis, and blindly evaluated by an experienced pathologist. The study and sample collection were performed after informed consent and Institutional Review Board approval by the Donostia University Hospital (San Sebastian, Spain), in accordance with the Declaration of Helsinki.

\section{Histopathology and serum analyses}

Paraffin-embedded sections $(3-4 \mu \mathrm{m})$ were stained with hematoxylin and eosin (H\&E) and Masson's Trichrome, using standard protocols. Liver sections were scored in a blinded fashion by experienced pathologists, using a 4-point severity scale ( 0 , normal; 1 , mild; 2 , moderate; 3 , severe), for necrosis and hydropic degeneration. Each liver specimen was assessed for the presence of hepatocellular degeneration, defined as the sum of necrosis and hydropic degeneration. Serum levels of ALT, alkaline phosphatase AP and bile acids were determined using standard clinical chemistry techniques.

\section{Total RNA extraction from mouse hepatocytes and formalin-fixed, paraffin-embedded (FFPE) slices}

Total RNA from primary mouse hepatocytes and from animal liver samples was extracted using the TRIzol reagent according to the manufacturer's instructions (Thermo Fisher Scientific, Inc.). Liver tissue sections $(4-5 \mu \mathrm{m})$ were deparaffinized, hydrated and washed with PBS. Liver tissue was collected and digested with $40 \mu \mathrm{g} / \mathrm{mL}$ proteinase $\mathrm{K}$ at $56^{\circ} \mathrm{C}$ for $30 \mathrm{~min}$ with shaking $(500 \mathrm{rpm})$, followed by an incubation at $80^{\circ} \mathrm{C}$ for $15 \mathrm{~min}$ and finally at $4^{\circ} \mathrm{C}$ for $5 \mathrm{~min}$. Each sample was homogenized using a motor-driven grinder on $1 \mathrm{~mL}$ TRIzol reagent. After mixing with $0.2 \mathrm{~mL}$ 
chloroform, each sample was centrifuged at $12,000 \mathrm{~g}$ for 15 $\min$ at $4{ }^{\circ} \mathrm{C}$ and the aqueous phase recovered. Total RNA was precipitated by incubation with $0.5 \mathrm{~mL}$ isopropyl alcohol at $-20^{\circ} \mathrm{C}$ for $2 \mathrm{~h}$. Samples were centrifuged at $12,000 \mathrm{~g}$ for $10 \mathrm{~min}$ at $4{ }^{\circ} \mathrm{C}$ and the RNA pellet was washed with $75 \%$ ethanol. RNA pellets were air dried and resuspended in $20 \mu \mathrm{L}$ RNase-free water. The purity of RNA was checked by confirming the ratio of the absorbance readings at 260 and $280 \mathrm{~nm}$ in a range of $1.9-2.1$.

\section{Quantitative RT-PCR (qPCR)}

Total RNA was converted into cDNA using NZY Reverse Transcriptase (NZYTech, Lisbon, Portugal), according to the manufacturer's instructions. Real-time RT-PCR was performed in the QuantStudio ${ }^{\mathrm{TM}} 7$ Flex Real-Time PCR System (Thermo Fisher Scientific Inc.). The following primer sequences were used: for the Mip-2 gene, 5' GCT ACG AAC TGC CTG ACG G 3' (forward) and 5' GCT GTT ATA GGT GGT TTC GTG GA $3^{\prime}$ (reverse); for the $I l-1 \beta$ gene, 5' TGC CAC CTT TTG ACA GTG ATG 3' (forward) and 5' TGA TGT GCT GCT GCG AGA TT 3' (reverse); for the Tlr4 gene, 5' TCC CTG CAT AGA GGT AGT TCC TA 3' (forward) and 5' CTT CAA GGG GTT GAA GCT CAG 3' (reverse); for the $T g f-\beta$ gene, 5' CTG CTG ACC CCC ACT GAT AC 3'(forward) and 5' GTG AGC GCT GAA TCG AAA GC 3' (reverse); for $\alpha$-Sma gene, 5' GCT ACG AAC TGC CTG ACG G 3' (forward) and 5' GCT GTT ATA GGT GGT TTC GTG GA 3' (reverse); for the collagen- $1 \alpha 1$ gene 5' CTG ACT GGA AGA GCG GAG AG 3' (forward) and 5' GAC GGC TGA GTA GGG AAC AC 3' (reverse); for the $\mathrm{Ho}-1$ gene 5' CGG GC AGC AAC AAA GTG 3' (forward) and 5' AGT GTA AGG ACC CAT CGG AGA A 3' (reverse); for the Fxr gene, 5' GGC TGC AAA GGT TTC TTC CG 3'(forward) and 5' CAG CCA ACA TCC CCA TCT CT 3' (reverse); for the Pxr gene, 5' TCA AGG ATT TCC GGC TGC G 3' (forward) and 5' GTA GGT TGA CAC ATC GGC CA 3' (reverse); for the Lxr gene, 5' TGT GCG CTC AGC TCT TGT C 3' (forward) and 5' CTC CGT TGC AGA ATC AGG AGA A 3' (reverse); for the Cyp7al gene, 5' CTG GGG GAT TGC TGT GGT AG 3' (forward) and 5' GCA CAG CCC AGG TAT GGA AT 3' (reverse); for the Sult2al gene, 5' ACC CCA AGT CAG GAA CGA AC 3' (forward) and 5' GGA TCC ACT TCG GAT CTC CC 3' (reverse); for the Oatp gene, 5' CCA AGA CTG CTG GTG CTT TG 3' (forward) and 5' AAT GAC CGC CTA CCC TAT GC 3' (reverse); for the Ntcp gene, 5' ACT GGC TTC CTG ATG GGC TAC 3' (forward) and 5' GAG TTG GAC GTT TTG GAA TCCT 3' (reverse); for the canalicular Mrp3 gene, 5' ATT GCC TCC AAT CGA TGG CT 3' (forward) and 5' GAT CAC TGC AAA CAG TGC GG 3' (reverse); for the Bsep gene 5' CAA TGT TCA GTT CCT CCG TTC A 3' (forward) and 5' TCT
CTT TGG TGT TGT CCC CAT A 3' (reverse); and for the hypoxanthine phosphoribosyltransferase (Hprt) gene, 5' GGT GAA AAG GAC CTC TCG AAG TG 3' (forward) and 5' ATA GTC AAG GGC ATA TCC AAC AAC A 3' (reverse). Two independent reactions for each primer set were performed in a total volume of $12.5 \mu \mathrm{L}$ containing $2 \times$ Power SYBR green PCR master mix (Thermo Fisher Scientific, Inc.) and $0.6 \mu \mathrm{M}$ of each primer. The relative amounts of each gene were calculated based on the standard curve normalized to the level of HPRT and expressed as fold change from sham WT control. To quantitate the relative amounts of Rip3, Mlkl, and Cdk2apl, total RNA was converted into cDNA using High-Capacity RNA-tocDNA $^{\text {TM }}$ Kit (Thermo Fisher Scientific, Inc.), according to the manufacturer's instructions. Real-time RT-PCR was performed using the TaqMan ${ }^{\circledR}$ Gene Expression Assay (Thermo Fisher Scientific, Inc.) following the manufacturer's instructions. For miR-21, the TaqMan ${ }^{\circledR}$ Gene Expression Assay was used (Thermo Fisher Scientific, Inc.). $\beta$-2-microglobulin $(B 2 m)$ and U6 were used as the normalization control of genes and miR-21, respectively. Relative amounts of $m i R-21$ and each gene were determined by the threshold cycle $\left(2^{-\Delta \Delta C t}\right)$ method.

\section{Analysis of liver hydroxyproline content, lipid peroxidation, total ROS and caspase-3/-7 and -8 activities}

Total collagen content in the liver was measured by colorimetric determination of the collagen-specific amino acid hydroxyproline using a commercial kit (Hydroxyproline Assay Kit; Sigma-Aldrich Co., St Louis, MO, USA), according to the manufacturer's instructions. Briefly, $10 \mathrm{mg}$ of liver tissue was homogenized using a motor-driven grinder on $100 \mu \mathrm{L}$ of water. After acid hydrolysis of collagen, samples were oxidized with chloramine $\mathrm{T}$, followed by enzymatic reaction with 4-dimethylaminobenzaldehyde (DMAB). Sample absorbance was measured at $560 \mathrm{~nm}$ using the GloMax-Multi+Detection System (Promega Corp., Madison, WI, USA) and data expressed as $\mu \mathrm{g}$ of hydroxyproline per milligram of wet liver.

The amount of aldehyde end products of lipid peroxidation, namely malondialdehyde, was analyzed in whole liver lysates using a commercial kit (Lipid Peroxidation (MDA) Assay Kit; Sigma-Aldrich Co.), as previously described [8]. ROS levels and caspase-3/-7 and -8 activities were analyzed in whole liver lysates through the use of $2^{\prime}, 7^{\prime}$-dichlorodihydrofluorescein diacetate ( $\left.\mathrm{H}_{2} \mathrm{DCFDA}\right)$ (Sigma-Aldrich Co.), and Caspase-Glo® 3/7 and 8 assays (Promega Corp.), respectively, as mentioned before [8].

\section{TUNEL assay}

TUNEL assay was performed in tissue cryosections $(5 \mu \mathrm{m})$ using the ApopTag® Red In Situ Apoptosis Detection Kit, 
according to the manufacturer's instructions (Merck Millipore, Darmstadt, Germany). Nuclei were counterstained with Hoechst 33258 (Sigma-Aldrich Co.) at $50 \mu \mathrm{g} / \mathrm{mL}$ in PBS for $10 \mathrm{~min}$ at room temperature. Six images per sample were obtained and fluorescent red nuclei were considered TUNEL-positive cells. Data is expressed as the number of TUNEL-positive cells per $\mathrm{mm}^{2}$.

\section{Iron measurement}

Total iron was measured in murine livers as previously described $[8,46]$. The quantity of iron was normalized by the dry tissue mass. This assay measures primarily labile iron, although residual heme detection cannot be excluded.

\section{Cell culture and treatments}

Primary mouse hepatocytes were isolated from female WT, RIP3-deficient $\left(\right.$ Rip3 $\left.^{-I-}\right)$ and miR-21-deficient $\left(m i R-21^{-I-}\right)$ mice as previously described [28,47]. After isolation, hepatocytes were resuspended in Complete William's E medium (Sigma-Aldrich Co.) and plated on Primaria ${ }^{\mathrm{TM}}$ tissue culture dishes (BD Biosciences, San Jose, CA, USA) at $5 \times 10^{4}$ cells $/ \mathrm{cm}^{2}$. Cells were maintained at $37^{\circ} \mathrm{C}$ in a humidified atmosphere of $5 \% \mathrm{CO}_{2}$ for $4 \mathrm{~h}$, to allow attachment. Primary mouse hepatocytes were pretreated with $50 \mu \mathrm{M}$ of a pan-caspase inhibitor, zVAD-fmk (Enzo Life Sciences Inc., Farmingdale, NY, USA), or dimethyl sulfoxide (DMSO; Sigma-Aldrich Co.) vehicle control (final concentration of $0.1 \%$ ). After $1 \mathrm{~h}$, cells were exposed to TNF- $\alpha(10 \mathrm{ng} / \mathrm{mL})$ (PeproTech EC Ltd., London, UK) plus cycloheximide (CHX; $0.5 \mu \mathrm{g} / \mathrm{mL}$ ) (Sigma-Aldrich Co.) or vehicle control. After $36 \mathrm{~h}$, cells were harvested for cell death assays and protein extraction.

For functional analyses, primary mouse hepatocytes were transfected $4 \mathrm{~h}$ after platting with $20 \mathrm{pM}$ of a specific miR21 precursor (pre-miR-21; Ambion, Thermo Fisher Scientific Inc.) or with a pre-miR negative control (pre-miRControl; Ambion, Thermo Fisher Scientific Inc.), using Lipofectamine $3000^{\mathrm{TM}}$ (Invitrogen, Thermo Fisher Scientific Inc.), according to manufacturer's instructions. Alternatively, primary mouse hepatocytes were transfected $4 \mathrm{~h}$ after platting with $40 \mathrm{pM}$ of a short interference RNA (siRNA) nucleotide against pten (siPTEN; Ambion, Thermo Fisher Scientific Inc.), $p d c d 4$ (siPDCD4; Ambion, Thermo Fisher Scientific Inc.), cdk2apl (siCDK2AP1; Ambion, Thermo Fisher Scientific Inc.) or a siRNA control (siControl; Ambion, Thermo Fisher Scientific Inc.), using Lipofectamine $3000^{\mathrm{TM}}$. At $16 \mathrm{~h}$ post-transfection, cells were pretreated $1 \mathrm{~h}$ with zVAD-fmk before incubation with TNF$\alpha / \mathrm{CHX}$. After $28 \mathrm{~h}$, cells were harvested for cell death assays and total RNA and protein extractions. To ascertain miR-21-dependent modulation of CDK2AP1, WT hepatocytes were co-transfected with $150 \mathrm{ng}$ of a reporter plasmid driven by the SV40 basal promoter, harboring a CDK2AP1 3' untranslated region (UTR) (MmiT031127MT06; GeneCopoeia ${ }^{\mathrm{TM}}$, Rockville, USA) or a negative control region (CmiT000001-MT06, GeneCopoeia ${ }^{\mathrm{TM}}$ ) upstream of the humanized firefly luciferase gene, and premiR-21/pre-miR-Control; CDK2AP1/Control siRNAs; or anti-miR-21/anti-miR-Control, for $24 \mathrm{~h}$. Reporter plasmids also contain the Renilla luciferase gene, that was used for normalization purposes. Reporter assays were performed using the Dual-Luciferase ${ }^{\circledR}$ Reporter Assay (Promega Corp.), according to the manufacture's specifications.

In addition, L929 cells were transfected during platting with $40 \mathrm{pM}$ of pre-miR-21/pre-miR negative control or with $40 \mathrm{pM}$ of a miR-21 specific inhibitor (anti-miRNA-21; Ambion, Thermo Fisher Scientific Inc.) / anti-miRNA negative control, using Lipofectamine $3000^{\mathrm{TM}}$. After $24 \mathrm{~h}$, cells were treated with TNF- $\alpha(10 \mathrm{ng} / \mathrm{mL})$ for $7 \mathrm{~h}$ and then processed for adenylate kinase (AK) release assay, as a measure of general cell death.

\section{Total and soluble/insoluble protein extraction and immunoblotting}

Total and soluble/insoluble protein extraction was performed as previously described [5]. Steady-state levels of MLKL, p-MLKL, PTEN, PDCD4, CDK2AP1, RIP3, caspase-3, JNK, and phosphorylated JNK (p-JNK) were determined by immunoblot analysis. Briefly, $50 \mu \mathrm{g}$ of total protein extracts, insoluble or soluble protein fractions were separated on an 8 or $12 \%$ sodium dodecyl sulfate-polyacrylamide gel electrophoresis (SDS-PAGE). Following electrophoretic transfer onto nitrocellulose membranes and blocking with $5 \%$ milk solution, blots were incubated overnight at $4{ }^{\circ} \mathrm{C}$ with primary rabbit polyclonal antibodies against p-MLKL (1:1000, ab196436, Abcam plc, Cambridge, UK), MLKL (1:500, SAB1302339, Sigma-Aldrich Co.), PTEN (1:1000, D4.3, Cell Signaling Technology, Inc., Danvers, MA, USA), PDCD4 (1:500, sc-27123; Santa Cruz Biotechnology Inc., Dallas, TX, USA) CDK2AP1 (1:200, sc-390283, Santa Cruz Biotechnology Inc.), RIP3 (1:1000, AHP1797, AbD Serotec, Bio-Rad Laboratories, Hercules, CA, USA), caspase-3 (1:100, sc-7148, Santa Cruz Biotechnology Inc.), p-JNK (1:200, sc-6254, Santa Cruz Biotechnology Inc.), JNK (1:500, sc-1648, Santa Cruz Biotechnology Inc.) and with a secondary antibody conjugated with horseradish peroxidase (Bio-Rad Laboratories) diluted 1:5000 in blocking solution for $1 \mathrm{~h}$ at room temperature. Membranes were processed for protein detection using Super Signal substrate (Pierce, Thermo Fisher Scientific). $\beta$-actin (1:20000; A5541; Sigma-Aldrich Co.) was used as loading control. 


\section{Cell death assays}

The percentage of general cell death was evaluated using the lactate dehydrogenase (LDH) Cytotoxicity Detection Kit ${ }^{\mathrm{PLUS}}$ (Roche Diagnostics GmbH, Mannheim, Germany), following the manufacturer's instructions. Experimental LDH values were normalized with maximum releasable LDH activity of cells, after cell disruption with the provided lysis solution. Alternatively, the CytoTox-Fluor ${ }^{\mathrm{TM}}$ Cytotoxicity Assay (Promega Corp.) was used to measure the relative number of dead cells through measurement of a distinct protease activity associated with cytotoxicity using the fluorogenic peptide substrate bis-alanyl-alanyl-phenylalanyl-rhodamine 110 (bisAAF-R110), according to the manufacturer's instructions. Finally, in L929 cells general cell death was determined in culture media of each well added bioluminescent cytolysis assay, designed to measure the release of adenylate kinase (AK) enzyme from damaged cells (ToxiLight ${ }^{\mathrm{TM}}$ BioAssay Kit, Lonza, Basel, Switzerland).

\section{Densitometry and statistical analysis}

The relative intensities of protein bands were analyzed using the Image Lab densitometric analysis program (version 5.1; Bio-Rad Laboratories). Statistical analysis included Student's $t$-test when appropriate or 1-way analysis of variance (ANOVA) with Bonferroni post hoc testing when more than two groups were compared. Values of $p<0.05$ were considered statistically significant. All statistical analysis was performed with GraphPad Prism 5 software (GraphPad Software, Inc., San Diego, CA, USA).

Acknowledgements The authors thank Prof. Eric Olson, Southwestern Medical Center, University of Texas, for kindly providing $m i R-21^{-1-}$ mice, as well as Dr. Vishva Dixit, Molecular Oncology Department, Genentech, Inc. (San Fransisco, CA, USA) and Dr. Miguel Soares, Instituto Gulbenkian de Ciência (Oeiras, Portugal) for kindly providing Rip $^{--}$mice. We also thank Dolores Bonaparte, Rodent Facility, Instituto de Medicina Molecular for the training in BDL, and Elisa Alves from Clinical Analyses Core Laboratory, Faculty of Pharmacy, Universidade de Lisboa, Lisbon, Portugal for routine clinical analyses. Finally, we thank all members of the laboratory for insightful discussions. The study was supported in part by Fundação para a Ciência e a Tecnologia through grants PTDC/BIM-MEC/0895/2014 and UID/ DTP/04138/2013, and fellowships SFRH/BD/91119/2012 (MBA), SFRH/BD/88212/2012 (PMR), and SFRH/BD/104160/201 (ALS).

\section{Compliance with ethical standards}

Conflict of interest The authors declare that they have no competing interests.

\section{References}

1. Vanden Berghe T, Linkermann A, Jouan-Lanhouet S, Walczak H, Vandenabeele P. Regulated necrosis: the expanding network of non-apoptotic cell death pathways. Nat Rev Mol Cell Biol. 2014;15:135-47.

2. Galluzzi L, Bravo-San Pedro JM, Vitale I, Aaronson SA, Abrams JM, Adam D, et al. Essential versus accessory aspects of cell death: recommendations of the NCCD 2015. Cell Death Differ. 2015;22:58-73.

3. Wang H, Sun L, Su L, Rizo J, Liu L, Wang LF, et al. Mixed lineage kinase domain-like protein MLKL causes necrotic membrane disruption upon phosphorylation by RIP3. Mol Cell. 2014;54:133-46.

4. Cai Z, Jitkaew S, Zhao J, Chiang HC, Choksi S, Liu J, et al. Plasma membrane translocation of trimerized MLKL protein is required for TNF-induced necroptosis. Nat Cell Biol. 2014;16:55-65.

5. Afonso MB, Rodrigues PM, Carvalho T, Caridade M, Borralho P, Cortez-Pinto $\mathrm{H}$, et al. Necroptosis is a key pathogenic event in human and experimental murine models of non-alcoholic steatohepatitis. Clin Sci. 2015;129:721-39.

6. Gautheron J, Vucur M, Reisinger F, Vargas Cardenas D, Roderburg C, Koppe C, et al. A positive feedback loop between RIP3 and JNK controls non-alcoholic steatohepatitis. EMBO Mol Med. 2014;6:1062-74.

7. Roychowdhury S, McMullen MR, Pisano SG, Liu X, Nagy LE. Absence of receptor interacting protein kinase 3 prevents ethanolinduced liver injury. Hepatology 2013;57:1773-83.

8. Afonso MB, Rodrigues PM, Simao AL, Ofengeim D, Carvalho T, Amaral JD, et al. Activation of necroptosis in human and experimental cholestasis. Cell Death Dis. 2016;7: e2390.

9. Lazaridis KN, LaRusso NF. The Cholangiopathies. Mayo Clin Proc. 2015;90:791-800.

10. Georgiev P, Jochum W, Heinrich S, Jang JH, Nocito A, Dahm F, et al. Characterization of time-related changes after experimental bile duct ligation. Br J Surg. 2008;95:646-56.

11. Valencia-Sanchez MA, Liu J, Hannon GJ, Parker R. Control of translation and mRNA degradation by miRNAs and siRNAs. Genes Dev. 2006;20:515-24.

12. Zamore PD, Haley B. Ribo-gnome: the big world of small RNAs. Science. 2005;309:1519-24.

13. Ma X, Conklin DJ, Li F, Dai Z, Hua X, Li Y, et al. The oncogenic microRNA miR-21 promotes regulated necrosis in mice. Nat Commun.2015;6:7151

14. Selaru FM, Olaru AV, Kan T, David S, Cheng Y, Mori Y, et al. MicroRNA-21 is overexpressed in human cholangiocarcinoma and regulates programmed cell death 4 and tissue inhibitor of metalloproteinase 3. Hepatology. 2009;49:1595-601.

15. Meng F, Henson R, Wehbe-Janek H, Ghoshal K, Jacob ST, Patel T. MicroRNA-21 regulates expression of the PTEN tumor suppressor gene in human hepatocellular cancer. Gastroenterology. 2007;133:647-58.

16. Dattaroy D, Pourhoseini S, Das S, Alhasson F, Seth RK, Nagarkatti M, et al. Micro-RNA 21 inhibition of SMAD7 enhances fibrogenesis via leptin-mediated NADPH oxidase in experimental and human nonalcoholic steatohepatitis. Am J Physiol Gastrointest Liver Physiol. 2015;308:G298-312.

17. Loyer X, Paradis V, Henique C, Vion AC, Colnot N, Guerin CL, et al. Liver microRNA-21 is overexpressed in non-alcoholic steatohepatitis and contributes to the disease in experimental models by inhibiting PPARalpha expression. Gut. 2016;65:1882-94.

18. Rodrigues PM, Afonso MB, Simao AL, Carvalho CC, Trindade A, Duarte A, et al. miR-21 ablation and obeticholic acid ameliorate nonalcoholic steatohepatitis in mice. Cell Death Dis. 2017;8: e2748.

19. Kennedy LL, Meng F, Venter JK, Zhou T, Karstens WA, Hargrove LA, et al. Knockout of microRNA-21 reduces biliary 
hyperplasia and liver fibrosis in cholestatic bile duct ligated mice. Lab Invest. 2016;96:1256-67.

20. Rieger JK, Klein K, Winter S, Zanger UM. Expression variability of absorption, distribution, metabolism, excretion-related microRNAs in human liver: influence of nongenetic factors and association with gene expression. Drug Metab Dispos. 2013;41:1752-62.

21. Canbay A, Feldstein A, Baskin-Bey E, Bronk SF, Gores GJ. The caspase inhibitor IDN-6556 attenuates hepatic injury and fibrosis in the bile duct ligated mouse. J Pharmacol Exp Ther. 2004;308:1191-6.

22. Kluwe J, Pradere JP, Gwak GY, Mencin A, De Minicis S, Osterreicher $\mathrm{CH}$, et al. Modulation of hepatic fibrosis by c-Jun-Nterminal kinase inhibition. Gastroenterology. 2010;138:347-59.

23. Calo N, Ramadori P, Sobolewski C, Romero Y, Maeder C, Fournier M, et al. Stress-activated miR-21/miR-21* in hepatocytes promotes lipid and glucose metabolic disorders associated with high-fat diet consumption. Gut. 2016;65:1871-81.

24. Liu Y, Binz J, Numerick MJ, Dennis S, Luo G, Desai B, et al. Hepatoprotection by the farnesoid X receptor agonist GW4064 in rat models of intra- and extrahepatic cholestasis. J Clin Invest. 2003;112:1678-87.

25. Stedman CA, Liddle C, Coulter SA, Sonoda J, Alvarez JG, Moore $\mathrm{DD}$, et al. Nuclear receptors constitutive androstane receptor and pregnane X receptor ameliorate cholestatic liver injury. Proc Natl Acad Sci USA. 2005;102:2063-8.

26. Uppal H, Saini SP, Moschetta A, Mu Y, Zhou J, Gong H, et al. Activation of LXRs prevents bile acid toxicity and cholestasis in female mice. Hepatology. 2007;45:422-32.

27. Tan Y, Pan T, Ye Y, Ge G, Chen L, Wen D, et al. Serum microRNAs as potential biomarkers of primary biliary cirrhosis. PLoS ONE. 2014;9:e111424.

28. Castro RE, Ferreira DM, Zhang X, Borralho PM, Sarver AL, Zeng $\mathrm{Y}$, et al. Identification of microRNAs during rat liver regeneration after partial hepatectomy and modulation by ursodeoxycholic acid. Am J Physiol Gastrointest Liver Physiol. 2010;299: G887-897.

29. Fischer S, Beuers U, Spengler U, Zwiebel FM, Koebe HG. Hepatic levels of bile acids in end-stage chronic cholestatic liver disease. Clin Chim Acta. 1996;251:173-86.

30. Rodrigues PM, Afonso MB, Simao AL, Borralho PM, Rodrigues $\mathrm{CM}$, Castro RE. Corrigendum: inhibition of NF-kappaB by deoxycholic acid induces miR-21/PDCD4-dependent hepatocellular apoptosis. Sci Rep. 2016;6:27828.

31. Wu H, Ng R, Chen X, Steer CJ, Song G. MicroRNA-21 is a potential link between non-alcoholic fatty liver disease and hepatocellular carcinoma via modulation of the HBP1-p53Srebp1c pathway. Gut. 2015;65:1850-60.

32. Ramachandran A, McGill MR, Xie Y, Ni HM, Ding WX, Jaeschke H. Receptor interacting protein kinase 3 is a critical early mediator of acetaminophen-induced hepatocyte necrosis in mice. Hepatology. 2013;58:2099-108.

33. Li J, McQuade T, Siemer AB, Napetschnig J, Moriwaki K, Hsiao YS, et al. The RIP1/RIP3 necrosome forms a functional amyloid signaling complex required for programmed necrosis. Cell. 2012;150:339-50.

34. Jacobsen AV, Lowes KN, Tanzer MC, Lucet IS, Hildebrand JM, Petrie EJ, et al. HSP90 activity is required for MLKL oligomerisation and membrane translocation and the induction of necroptotic cell death. Cell Death Dis. 2016;7:e2051.

35. Ofengeim D, Ito Y, Najafov A, Zhang Y, Shan B, DeWitt JP, et al. Activation of necroptosis in multiple sclerosis. Cell Rep. 2015;10:1836-49.

36. Rodriguez DA, Weinlich R, Brown S, Guy C, Fitzgerald P, Dillon $\mathrm{CP}$, et al. Characterization of RIPK3-mediated phosphorylation of the activation loop of MLKL during necroptosis. Cell Death Differ. 2016;23:76-88.

37. Gong YN, Guy C, Olauson H, Becker JU, Yang M, Fitzgerald P, et al. ESCRT-III acts downstream of MLKL to regulate necroptotic cell death and its consequences. Cell. 2017;169:286-300 e216

38. Sheedy FJ, Palsson-McDermott E, Hennessy EJ, Martin C, O'Leary JJ, Ruan Q, et al. Negative regulation of TLR4 via targeting of the proinflammatory tumor suppressor PDCD4 by the microRNA miR-21. Nat Immunol. 2010;11:141-7.

39. Allen K, Jaeschke H, Copple BL. Bile acids induce inflammatory genes in hepatocytes: a novel mechanism of inflammation during obstructive cholestasis. Am J Pathol. 2011;178:175-86.

40. Zheng J, Xue H, Wang T, Jiang Y, Liu B, Li J, et al. miR-21 downregulates the tumor suppressor P12 CDK2AP1 and stimulates cell proliferation and invasion. $\mathrm{J}$ Cell Biochem. 2011;112:872-80.

41. Hitomi J, Christofferson DE, Ng A, Yao J, Degterev A, Xavier RJ, et al. Identification of a molecular signaling network that regulates a cellular necrotic cell death pathway. Cell. 2008;135: 1311-23.

42. Ito Y, Ofengeim D, Najafov A, Das S, Saberi S, Li Y, et al. RIPK1 mediates axonal degeneration by promoting inflammation and necroptosis in ALS. Science. 2016;353:603-8.

43. Deshpande AM, Dai YS, Kim Y, Kim J, Kimlin L, Gao K, et al. Cdk2ap1 is required for epigenetic silencing of Oct4 during murine embryonic stem cell differentiation. J Biol Chem. 2009;284:6043-7.

44. Koo GB, Morgan MJ, Lee DG, Kim WJ, Yoon JH, Koo JS, et al. Methylation-dependent loss of RIP3 expression in cancer represses programmed necrosis in response to chemotherapeutics. Cell Res. 2015;25:707-25.

45. Newton K, Sun X, Dixit VM. Kinase RIP3 is dispensable for normal NF-kappa Bs, signaling by the B-cell and T-cell receptors, tumor necrosis factor receptor 1, and Toll-like receptors 2 and 4. Mol Cell Biol. 2004;24:1464-9.

46. Gozzelino R, Andrade BB, Larsen R, Luz NF, Vanoaica L, Seixas E, et al. Metabolic adaptation to tissue iron overload confers tolerance to malaria. Cell Host Microbe. 2012;12: 693-704.

47. Mariash CN, Seelig S, Schwartz HL, Oppenheimer JH. Rapid synergistic interaction between thyroid hormone and carbohydrate on mRNAS14 induction. J Biol Chem. 1986;261:9583-6. 